\title{
Cyclodextrin-Based Functional Glyconanomaterials
}

\author{
Gonzalo Rivero-Barbarroja ${ }^{1}{ }^{(}$, Juan Manuel Benito ${ }^{2}{ }^{\circledR}$, Carmen Ortiz Mellet ${ }^{1}{ }^{\circledR}$ \\ and José Manuel García Fernández ${ }^{2, * \mathbb{B}}$ \\ 1 Department of Organic Chemistry, Faculty of Chemistry, University of Seville, 41012 Seville, Spain; \\ grbarbarroja@us.es (G.R.-B.); mellet@us.es (C.O.M.) \\ 2 Instituto de Investigaciones Químicas (IIQ), CSIC, Universidad de Sevilla, 41092 Sevilla, Spain; \\ juanmab@iiq.csic.es \\ * Correspondence: jogarcia@iiq.csic.es; Tel.: +34-954489616
}

Received: 24 November 2020; Accepted: 12 December 2020; Published: 15 December 2020

\begin{abstract}
Cyclodextrins (CDs) have long occupied a prominent position in most pharmaceutical laboratories as "off-the-shelve" tools to manipulate the pharmacokinetics of a broad range of active principles, due to their unique combination of biocompatibility and inclusion abilities. The development of precision chemical methods for their selective functionalization, in combination with "click" multiconjugation procedures, have further leveraged the nanoscaffold nature of these oligosaccharides, creating a direct link between the glyco and the nano worlds. CDs have greatly contributed to understand and exploit the interactions between multivalent glycodisplays and carbohydrate-binding proteins (lectins) and to improve the drug-loading and functional properties of nanomaterials through host-guest strategies. The whole range of capabilities can be enabled through self-assembly, template-assisted assembly or covalent connection of $\mathrm{CD} /$ glycan building blocks. This review discusses the advancements made in this field during the last decade and the amazing variety of functional glyconanomaterials empowered by the versatility of the CD component.
\end{abstract}

Keywords: cyclodextrins; drug delivery; gene delivery; glyconanomaterials; glyconanoparticles; glycopolymers; glycotargeting; multivalency; self-assembly; supramolecular nanomaterials

\section{Introduction}

Cyclodextrins (CDs) are cyclic oligosaccharides with unique inside/outside distribution of hydrophobic/hydrophilic areas, resulting in well-defined topological amphiphilicity. This property confers CDs distinctive advantages to form inclusion complexes with lipophilic guest molecules as far as them entirely or partially entering the CD macro-ring cavity. The stability and water solubility of the guest can be improved in this manner, or the target guest can be captured, removed or masked, broadening application scopes. Indeed, the academic and (bio)technological interest for cyclodextrins has been historically dominated by their inclusion complex-formation ability, which has translated into numerous applications in fields like food [1,2], cosmetics [3], environment [4,5], and medicine [3,6-10].

Structurally, CDs are composed by $\alpha(1 \rightarrow 4)$-linked glucose units that feature a characteristic toroidal truncated-cone shape, in which glucose hydroxyls orient to the outer space flanking the upper and lower rims, while methinic protons ( $\mathrm{H}-5$ and $\mathrm{H}-3)$ point to the inner cavity. The hexamer $(\alpha C D)$, heptamer $(\beta C D)$ and octamer $(\gamma C D)$ representatives are commercially available. All three are nanometric objects that share the same torus height $(7.8 \AA)$, as defined by the monosaccharide dimensions, and differ on the external (13.7, 15.3 and $16.7 \AA$ ) and internal diameters $(5.7,7.8$ and $9.5 \AA$, respectively), the later determining their affinity towards size-variable guests (Figure 1) [11,12]. Conceptually, CDs can be considered as molecular nanoparticles in the sense advanced by Cheng and coworkers: nanometric molecular systems of natural or technological origin exhibiting persistent 
topology (shape and volume) $[13,14]$. They are susceptible to selective chemical manipulation to obtain sugary molecular nanosystems with tailored capabilities, or they can be used as functional components to engineer CD-based nanosystems benefiting from the CD inclusion properties [15-17]. Alternatively, they can be incorporated into polymeric, magnetic, lipid, metallic or mesoporous NPs to enhance their characteristics [18,19]. All these examples highlight the potential of CDs to galvanize positive synergies between research disciplines, such as synthetic chemistry, supramolecular chemistry, pharmaceutical formulation or materials science.
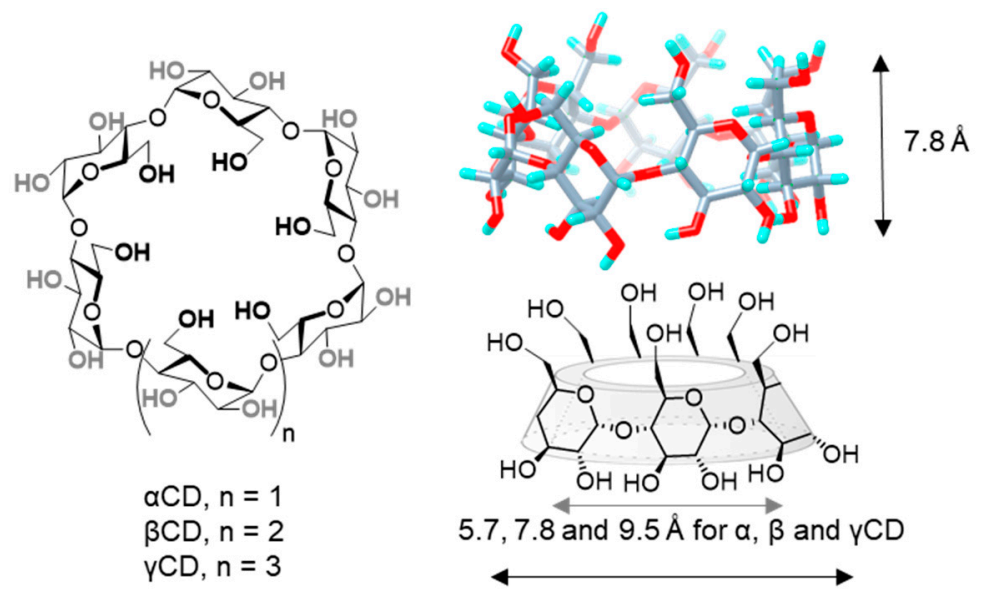

$13.7,15.3$ and $16.7 \AA$ for $\alpha, \beta$ and $\gamma C D$

Figure 1. Structures of $\alpha, \beta$ and $\gamma C D$ (left), 3D view of $\beta C D$ (upper-right) and schematic representation of $\mathrm{CD}$ basket-shape architecture (lower right), with indication of the height, and average internal and external diameters for the three commercially available representatives. CD, cyclodextrin.

Strictly speaking, CD-based nanomaterials can be considered as functional glyconanomaterials (CDs are definitely glyco) [20]. However, in the context of this thematic issue, this concept is reserved for nanomaterials exposing carbohydrate moieties mediating interactions with other biomolecular partners. By CD-based functional glyconanomaterials, here, we mean nanosized materials combining CD and glycan modules, either with an organic or inorganic core, obtained by self-assembly, template-assisted assembly or covalent conjugation. All these strategies will be discussed in this review, with an emphasis in the properties and applications of the resulting hybrid nanoconstructs. Note that molecular CD-glycan conjugates, widely used in fundamental studies on carbohydrate-protein interactions and in the design of glycotargeted CD drug carriers, are purposely excluded for the sake of consistency. Readers are eagerly encouraged to consult more comprehensive accounts on these topics for a wider view of the state-of-the-art [21-25]. The fabrication of glycosurfaces by exploiting (glyco) CD chemical and supramolecular properties is also not covered, and readers interested in this particular area of CD-based glycotechnology are addressed to recent reviews [16,26,27] and key contributions in the field [28-31].

\section{Multitopic Guest-Driven Clusterization of GlycoCDs}

Molecular scaffolds displaying two or more CD cavity-fitting motifs can behave, in principle, as multitopic guests, with the potential of forming high-order inclusion complexes. If the CD partner is a glycoCD, the total glycoligand valency of the resulting supramolecular species will grow with complex stoichiometry, which is expected to enhance the binding affinity towards complementary lectin receptors by virtue of the so-called multivalent or cluster effect [32-34]. The potential of this strategy in glycotargeting schemes was anticipated in 2004, in the context of a work aiming at developing an efficient carrier for the delivery of the taxane anticancer drug docetaxel (DTX, Taxotère ${ }^{\circledR}$ ) to macrophages [35]. DTX possesses two phenyl fragments that are well-suited for $\beta C D$ inclusion, whereas active uptake by macrophages can be promoted by targeting the macrophage mannose receptor (MMR). On such grounds, a trivalent $\beta C D$-mannosyl dendron conjugate was initially conceived. MMR binding 
studies evidenced a statistically significant increase in affinity in the presence of the drug, which is in agreement with the DTX-promoted clusterization of the conjugate. The association constant $\left(K_{\mathrm{a}}\right)$ of phenyl derivatives and $\beta C D\left(K_{\mathrm{a}} \approx 10^{3} \mathrm{M}\right)$ [36] is, however, too modest to warrant a medically useful concentration of the 2:1 complex in biological media, which was overcome by engineering a dimeric $\beta C D$-hexamannosyl dendron conjugate that formed a very strong 1:1 chelate-type complex with DTX (Figure 2).

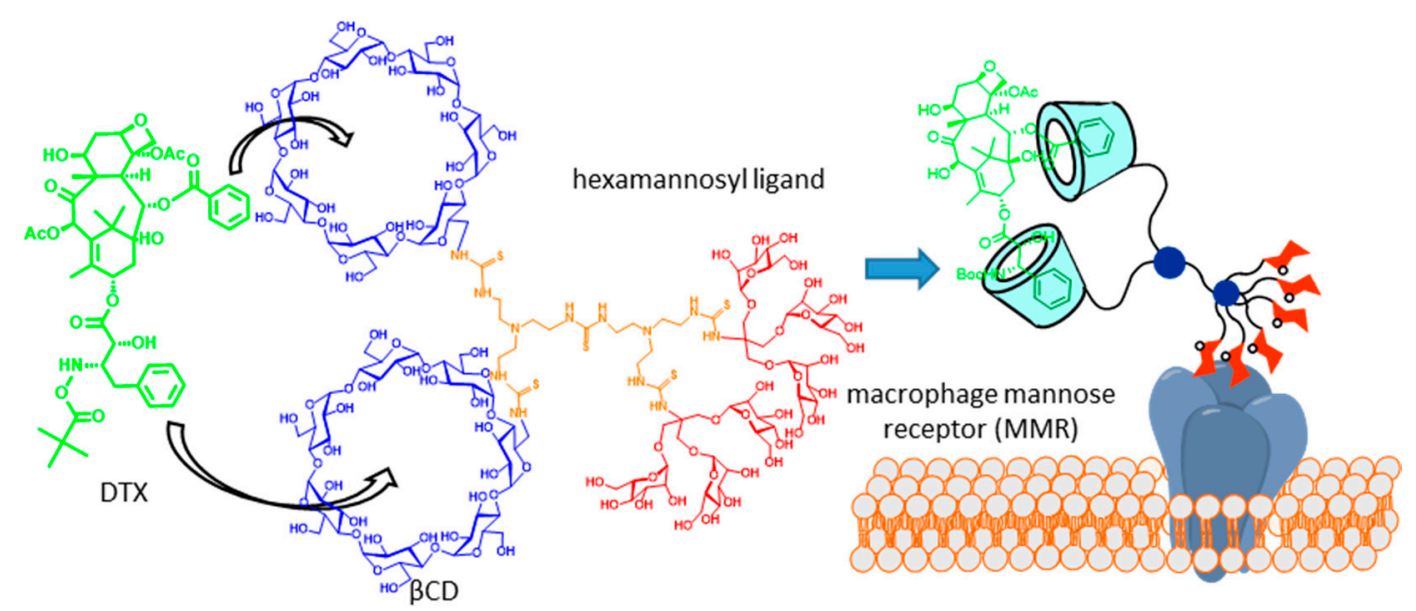

Figure 2. Docetaxel (DTX) carrier consisting of a hexamannosylated dimeric $\beta C D$ derivative designed on the basis of the drug clusterization concept [35]. Adapted with permission from Reference [3]. Copyright 2013 Royal Society of Chemistry.

Adamantane (Ad) derivatives form much more robust inclusion complexes with $\beta C D$ hosts than phenyl derivatives $\left(K_{\mathrm{a}} \approx 10^{5} \mathrm{M}\right)$. This property has been amply used for macromolecular materials design [37]. Notwithstanding, reports on $\beta C D /$ Ad host-guest supramolecular ligation chemistry using discrete molecular entities, for the purpose of assembling functional glyconanomaterials, are relatively scarce. In 2011, Seeberger and coworkers showed that the incorporation of up to six Ad moieties onto a fluorescent ruthenium(II)-bipyridine complex core provided a very convenient platform for the rapid construction of high-valent glyconanosensors for the visualization of carbohydrate-lectin interactions, just by mixing with sugar-appended $\beta C D$ derivatives (Figure 3a) [38]. A follow-up of this proof of concept was reported by Kikkeri and coworkers [39], who synthesized the two enantiomerically pure versions of the hexa-Ad guest (denoted $\Delta$ and $\Lambda$ for the positive and negative sign of the circular dichroism signal, respectively) and used them to build diastereomeric metallo-glycodendrimers by anchoring a heptamannosylated $\beta C D$ conjugate. Evaluation of the binding affinities towards different mannose-binding C-type lectins, including the human Dendritic Cell-Specific Intercellular adhesion molecule-3-Grabbing Non-integrin (CD-SIGN), the mouse-Specific Intracellular adhesion molecule-3 Grabbing Non-integrin homolog-Related 3 (SIGNR3) and Dectin-1, evidenced amazing differences that revealed a major impact of the chiral microenvironment in the recognition process, in spite of the similar topology of the supramolecular diastereomers. Such dissimilar behaviors were also confirmed in cellulo as well as in vivo. The same authors prepared metallo-glycodendrimers from a $\mathrm{Ru}(\mathrm{II})$ bipyridine complex that has attached only two Ad motifs and either a heptamannosylated or a heptagalactosylated $\beta C D$ component [40]. The glycodendrimers demonstrated selective carbohydrate-protein interaction properties and mediated the delivery of the $\mathrm{Ru}(\mathrm{II})$ complexes into cancer cells expressing specific mannose- or galactose-selective lectins, respectively. Once internalized, they showed cytotoxic activity by interacting with the endoplasmic reticulum (ER) and triggering caspase-mediated apoptosis, whereas they were not cytotoxic to normal cells (Figure 3b). 
(a)

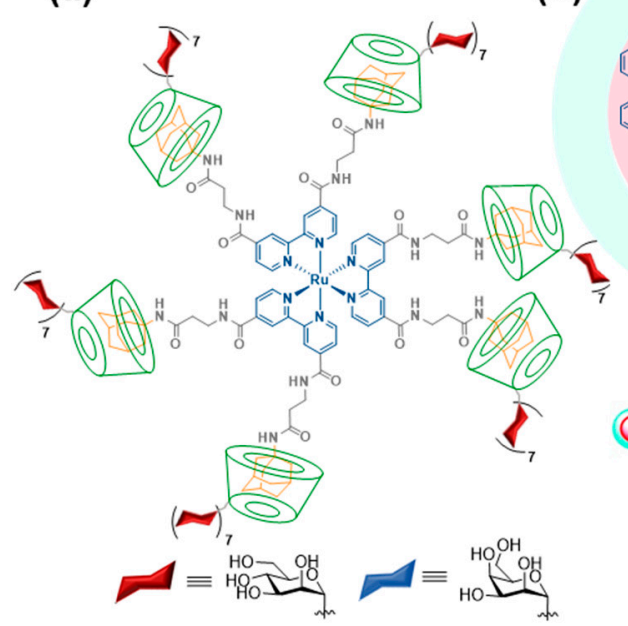

(b)

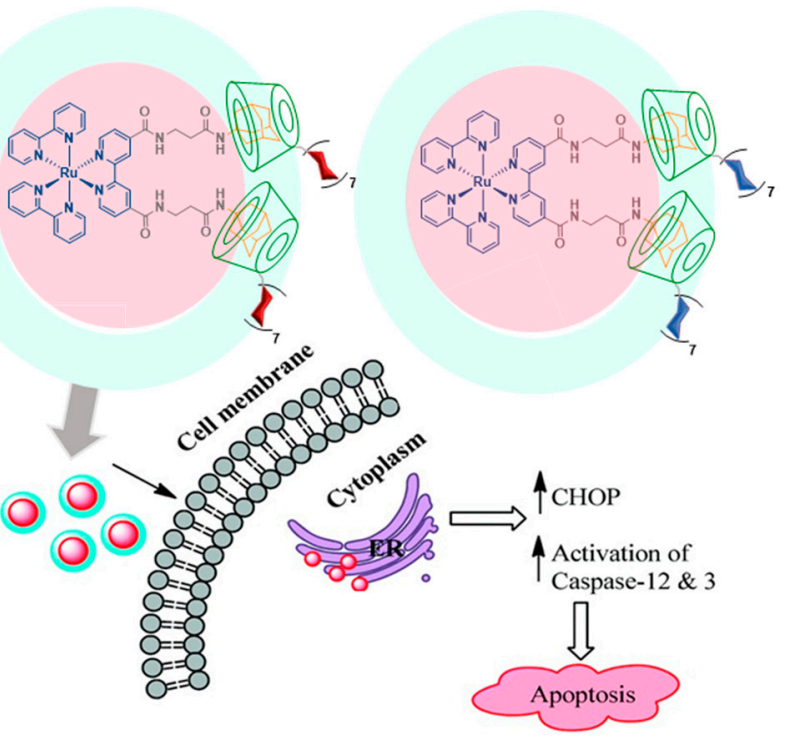

Figure 3. Heptamannosyl- $\beta \mathrm{CD} / \mathrm{Ru}$ (II)-scaffolded hexa-adamantyl host-guest complex reported by Seeberger and coworkers [38] (a) and bis-adamantyl analogs with anti-apoptotic activity reported by Kikkeri and coworkers [40] (b). Adapted with permission from Reference [40]. Copyright 2016 Royal Society of Chemistry.

Ferrocene and boron-dipyrromethene (BODIPY) have also been used as core elements for the construction of Ad guests, in order to clusterize glycoCDs into functional glyconanomaterials through inclusion complex formation. For instance, a ferrocene-bis-Ad guest was found to form a supramolecular dimer with a heptalactosyl- $\beta C D$ derivative that was employed to assess binding to the legume lectin peanut agglutinin (PNA), broadly used in fundamental studies on carbohydrate-protein recognition [41]. Zhang, Yin and coworkers prepared a BODIPY-tris-Ad derivative (BTA) and used it to prepare mannose-coated nanoparticles by the spontaneous supramolecular immobilization of a heptamannosylated- $\beta C D$ conjugate $\left(\mathrm{CD}-\mathrm{Man}_{7}\right)$ onto the surface of BTA aggregates upon co-precipitation (Figure 4) [42]. Transmission electron microscopy (TEM) revealed the formation of spherical BTA@CD-Man7 nanoparticles with an average diameter of $117 \pm 16 \mathrm{~nm}$, whereas confocal laser scanning microscopy (CLMS) showed that the nanoparticles were efficiently internalized in MDA-MB-231 breast cancer cells overexpressing the mannose receptor (MR), but not in healthy MCF-10A cells. The nanoparticles accumulated in the lysosomes of the cancer cells, where they dissociated and revealed the photosensitizer (PS) character of BODIPY. Irradiation with $665 \mathrm{~nm}$ light emitting diode (LED) light then resulted in phototoxicity. The potential of the mannose-mediated PS system for targeted photodynamic therapy (PDT) was confirmed in a mouse model that was established by injecting MDA-MB-231 cancer cells into subcutaneous tissues, confirming the remarkable tumor inhibition effect of BTA@CD-Man 7 under irradiation. 
(a)

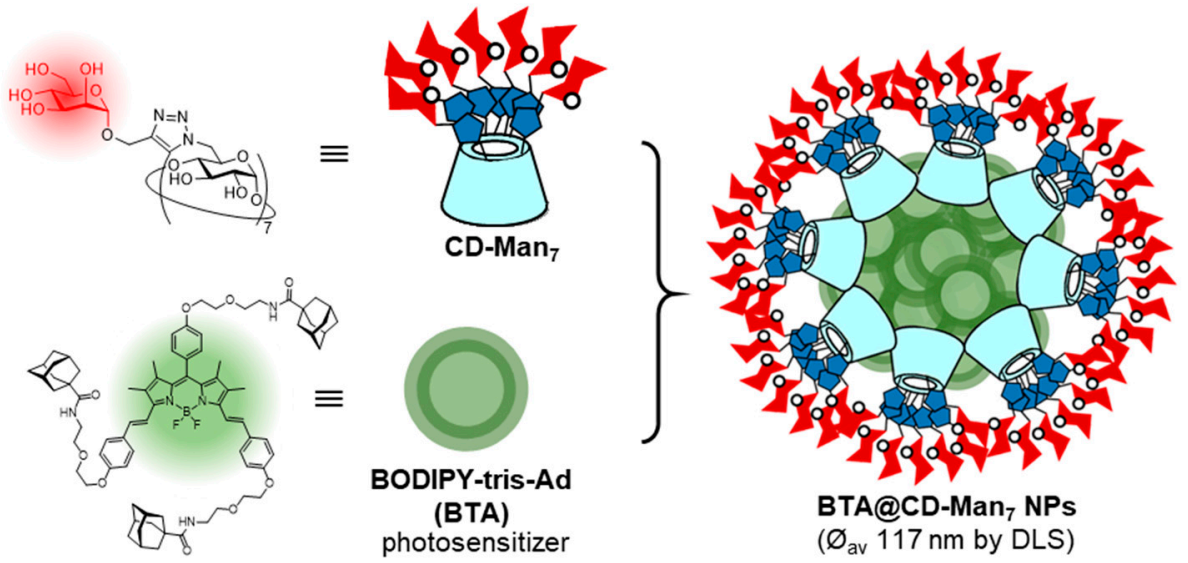

(b)

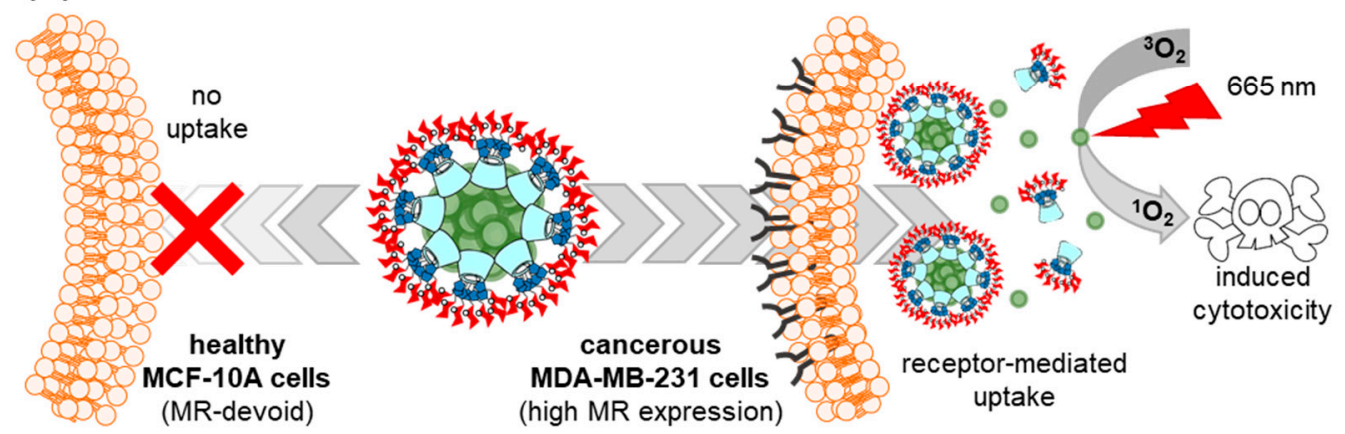

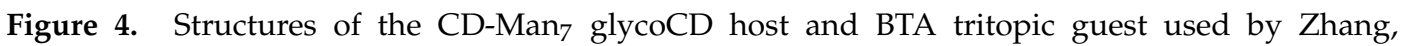
Yin and coworkers (a) and schematic representation of their self-assembly into nanoaggregates for targeted photodynamic therapy against breast cancer (b) [42]. CD, cyclodextrin; Man, mannose; BODIPY, boron-dipyrromethene; BTA, BODIPY-tris-Ad derivative; LSD, dynamic light scattering; MR, mannose receptor.

\section{Amphiphilicity as an Action Principle for GlycoCD Self-Assembly}

Inclusion complex formation can be exploited to impart self-assembling properties to $C D$ derivatives beyond multitopic guest-driven clusterization. For instance, if the guested molecule contains a hydrophobic tail, the resulting species will behave as a supramolecular amphiphile or "superamphiphile", a concept that emerged during the last decade and refers to surfactants where the hydrophilic and hydrophobic moieties are linked by noncovalent connections [43]. The implementation of this notion in the elaboration of nanocomplexes for the targeted delivery of drugs is particularly appealing due to the unique stimuli responsiveness of host-guest interactions $[44,45]$. Recently, Zhang and coworkers reported a superamphiphile construct encompassing a polyethylene glycol-tethered lactobionic acid- $\beta C D$ conjugate (LA-PEG- $\beta C D$ ) and a benzimidazole-modified doxorubicine (BM-DOX) as the hydrophilic and hydrophobic constituents respectively, intended for the treatment of hepatocellular carcinoma (HCC) [46]. LA is a ligand of the galactose-specific asialoglycoprotein receptor (ASGPR) at the surface of liver cancer cells. The BM module fits well in the cavity of $\beta C D$ : it was connected to the anticancer drug DOX through an acid-labile hydrazone functionality that was expected to be cleaved in the intracellular acidic environment with rapid release of DOX from the prodrug. In aqueous media, host-guest association between BM and $\beta C D$ brought together the targeted supramolecular prodrug (TSPD), which spontaneously self-assembled into spherical, biocompatible nanoparticles that exhibited a $\mathrm{pH}$-dependent drug release profile and excellent effects on HCC tumor cell growth (Figure 5). 

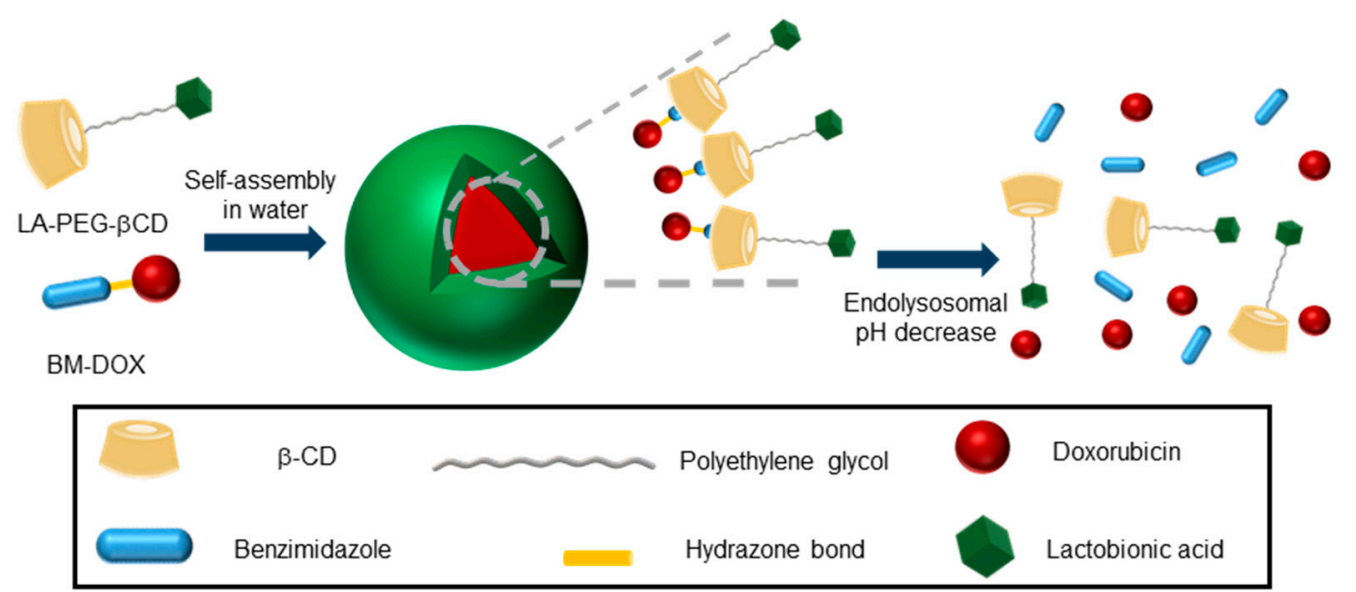

Figure 5. Schematic illustration of the superamphiphile strategy developed by Zhang and coworkers for the self-assembly of acid-sensitive ASGPR-targeted prodrug glyconanoparticles [46]. ASGPR, asialoglycoprotein receptor; LA, lactobionic acid; PEG, poly(ethylenglycol); $\beta C D$, $\beta$-cyclodextrin; BM, benzimidazole; DOX, doxorubicin.

The intrinsic two-face topology of $\mathrm{CDs}$ and the distinct reactivity of primary and secondary hydroxyls offers a convenient entry to covalent "classical" amphiphiles that can be tailored to self-assemble into different classes of aggregates (micelles, vesicles, nanospheres, nanocapsules) [17,47-49]. If the hydrophilic face in the amphiphilic CD is glyco-coated (glycoamphiphilic CDs; GaCDs), the corresponding self-assemblies will expose the glycan appendages to the bulk, available for their participation in biomolecular recognition processes. The interest of such systems for targeted drug delivery is obvious. Early work in the field was conducted by the groups of Nishimura, Darcy and Mazzaglia [50-54] and has already been reviewed [23]. Recent contributions by Seeberger, Yin and coworkers focus on the optimization of amphiphilic mannosylated $\beta C D$ derivatives in terms of self-assembling properties and stability of the resulting mannose-functionalized nanoparticles [55]. The authors encountered that installation of seven mannosyl residues at the primary rim through copper(II)-catalyzed azide-alkyne cycloaddition (CuAAC) "click" coupling [56] and propanoyl ester groups at the fourteen secondary hydroxyls afforded conjugates $\left(\mathrm{C}_{3}-\mathrm{CD}-\mathrm{Man}_{7}\right)$ that self-assembled in water. In this manner, they obtained spherical nanoparticles with an average diameter of $45 \mathrm{~nm}$ (TEM), an average hydrodynamic diameter of $112 \mathrm{~nm}$ (DLS), low polydispersity index (PDI, 0.109) and high stability under physiological conditions. $\mathrm{C}_{3}-\mathrm{CD}-\mathrm{Man}_{7}$ nanoparticles were able to encapsulate up to $12 \%$ of DOX, and the DOX-loaded system (DOX@C $\mathrm{C}_{3}-\mathrm{CD}-\mathrm{Man}_{7}$ ) efficiently delivered the drug to MR overexpressing MDA-MB-231 breast cancer cells in vitro and in vivo. The targeted drug delivery capabilities of $\mathrm{C}_{3}-\mathrm{CD}-\mathrm{Man}_{7}$ were further confirmed for the treatment of visceral leishmaniasis (VL) [57]. The resulting AmB\&DOX@ $\mathrm{C}_{3}-\mathrm{CD}-\mathrm{Man}_{7}$ nanomicelles were selectively taken up by RAW264.7 macrophages, with high expression of MR, and their therapeutic effect was established in vitro in RAW264.7 cells infected with L. donovani parasites. After treatment with AmB\&DOX@C $\mathrm{C}_{3}-\mathrm{CD}-\mathrm{Man}_{7}$, almost no parasite was detected, supporting that the formulation is a promising solution for VL therapy (Figure 6). 

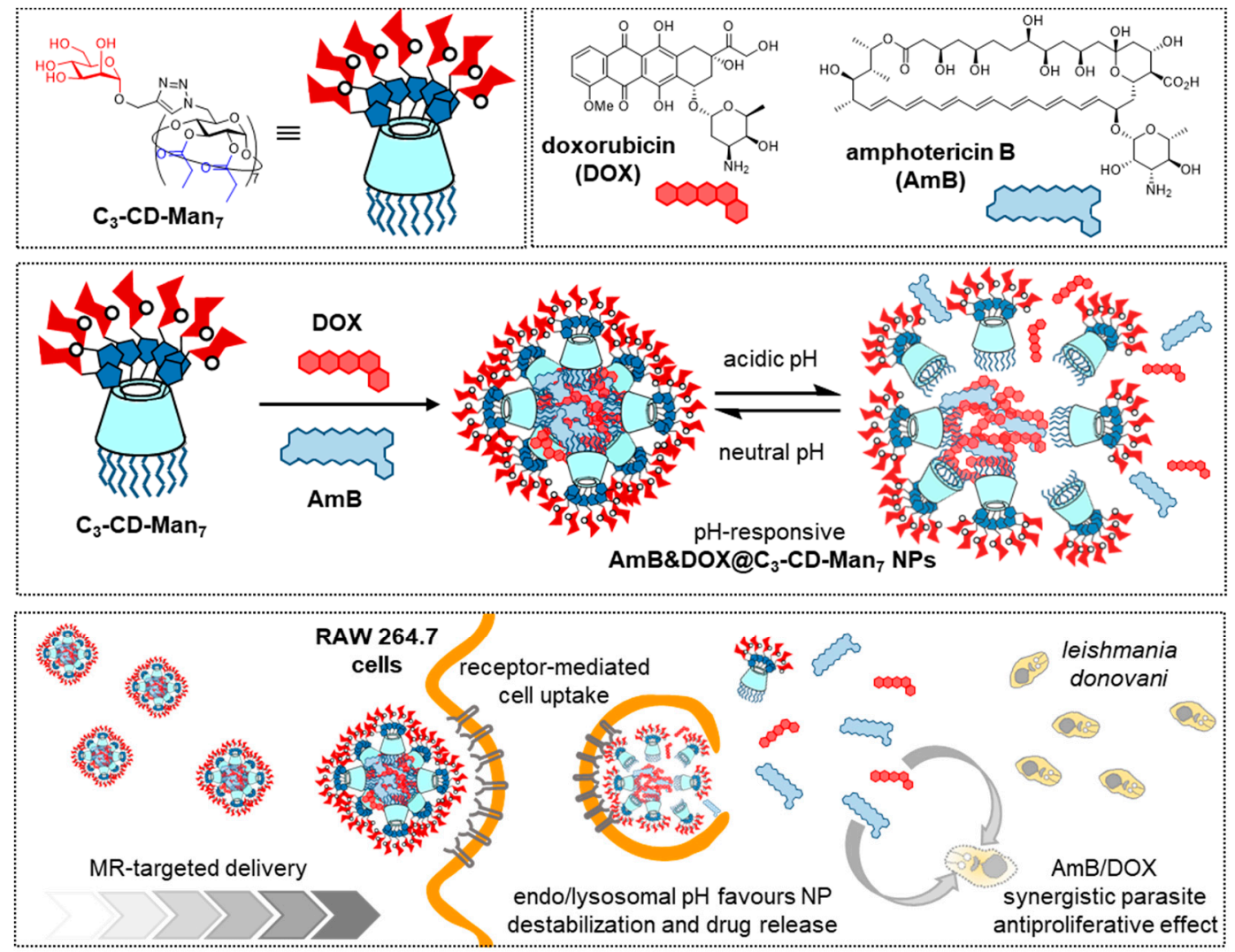

Figure 6. Structures of the $\mathrm{GaCD}$ derivative $\mathrm{C}_{3}-\mathrm{CD}-\mathrm{Man}_{7}$, doxorubicin (DOX) and amphotericin $\mathrm{B}(\mathrm{AmB})$ (upper panel) and schematic representations of their co-assembly to afford $\mathrm{pH}$-sensitive nanoparticles (Amb@DOX@C $\mathrm{C}_{3}-\mathrm{CD}-\mathrm{Man}_{7}$ ) (middle panel) and internalization in macrophages to treat visceral leishmaniasis (lower panel), as reported by Seeberger, Yin and coworkers [55,57]. GaCD, glycoamphiphilic cyclodextrin; Man, mannose; NP, nanoparticle.

\section{Tailoring Glycopolymer Topology by CD Inclusion-Promoted Macromolecular Folding and Self-Assembly}

The inclusion complexation between CDs, comprising CD units incorporated in polymers, and various guests has been extensively investigated in supramolecular chemistry [18]. However, although CD-containing polymers have been used in pharmaceutical applications since the 1980 's $[1,5,58,59]$, the profitable features of inclusion complexation did not sufficiently draw attention and therefore were not employed in macromolecular self-assembly until about the beginning of this century [60]. CDs are particularly valuable and extensively employed in tuning the amphiphilicity of macromolecules. For instance, if a fragment of a macromolecule containing a guest moiety is connected to CDs via inclusion complexation, this area will become more hydrophilic and thus the amphiphilicity of the complete macromolecule as a whole is altered. This strategy allows to control the self-assembly and the morphology of the assemblies [15]. In 2015, Bercer and coworkers extended the inclusion complexation-driven macromolecule-associated micellization strategy to the use of glyco-coated CDs [61]. The authors prepared an ABA triblock copolymer architecture having precisely positioned random poly( $N, N$-dimethylacrylamide) (PDMA)/poly(adamantane-acrylate) (PAdac) blocks within the first and the third blocks, while the middle block consisted of thermo-responsive poly( $N$-isopropylacrylamide) (PNIPAM) that enables the formation of a self-assembled micellar structure above the cloud point. The Ad-functionalized thermo-responsive triblock copolymer provided supramolecular host-guest interactions with $\beta C D$ as well as mono- and heptamannosylated $\beta C D$ derivatives (CD-Man 1 and $C D-M_{7}$ ). The resulting supramolecular amphiphilic macromolecule formed stable micelles in water as was clearly revealed by DLS. Quantitative concanavalin A (ConA; 
a mannose-specific plant lectin) precipitation assays demonstrated the accessibility of the mannosyl residues and their multivalent presentation at the surface of the assemblies, even in the case of the monomannosylated glycoCD, since lectin precipitation requires high carbohydrate density. Altogether, the results validated the $A d / \beta C D$ host-guest tactic for careful fine-tuning of the interaction between lectins and supramolecular glycopolymers (Figure 7).

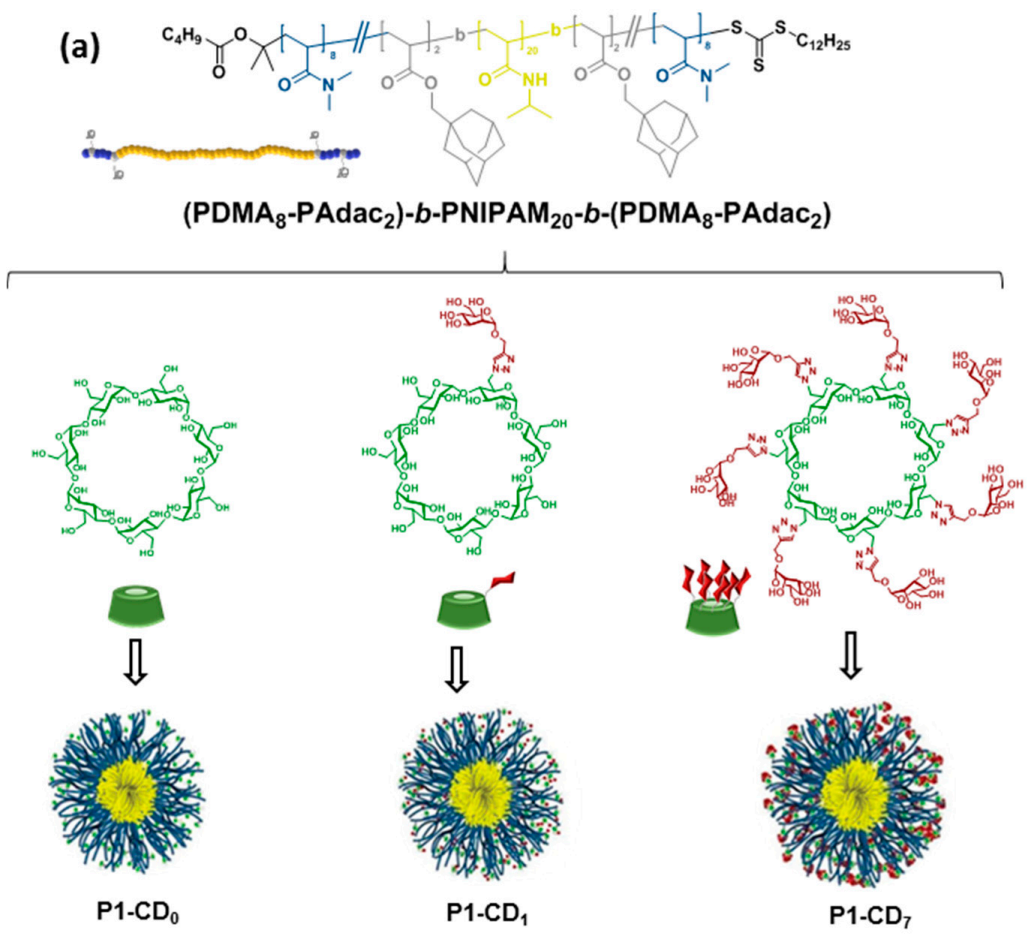

(b)

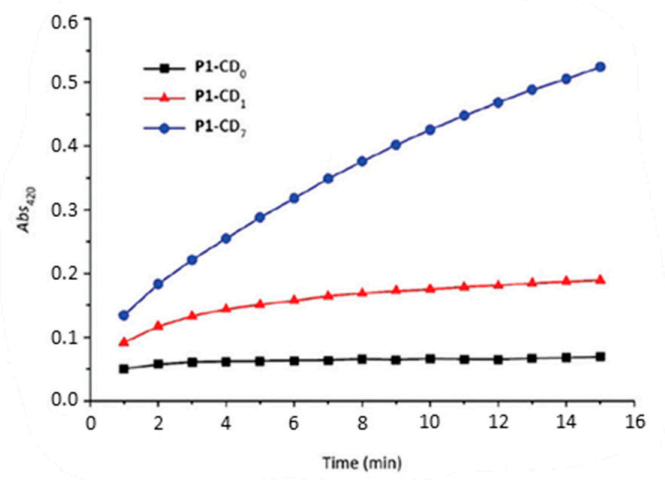

Figure 7. Average structure of the triblock copolymer (P1) and structures of the $\beta C D$ derivatives used by Bercer and coworkers [61] to self-assemble glycomicelles trough equimolecular mixing in water (a) and turbidity plots obtained upon mixing with concanavalin A (ConA) at $40{ }^{\circ} \mathrm{C}(\mathbf{b})$. Adapted with permission from Reference [61]. Copyright 2016 Royal Society of Chemistry. PDMA, poly(N,N-dimethylacrylamide); PNIPAM, poly( $N$-isopropyl acrylamide); PAdac, poly(adamantane-acrylate).

The alliance between CD supramolecular chemistry and living polymerization has been particularly fruitful at providing fascinating polymer materials [62]. Bercer and coworkers applied one of the most popular of such reactions, reversible addition-fragmentation chain transfer (RAFT), to create triblock glycocopolymers bearing $\beta C D$, Ad and mannose residues, combined with PDMA, in different blocks [63]. At sufficiently high dilution in aqueous solution, intermolecular host-guest interactions were prevented and only single-chain folding, promoted by intramolecular CD/Ad interactions, were observable by bidimensional nuclear Overhauser effect spectroscopy (2D NOESY) 
nuclear magnetic resonance (NMR) and dynamic light scattering (DLS). Folded glycopolymers were unfolded at high temperatures and also by addition of the competitive guest molecule 1-adamantylamine hydrochloride. Interestingly, the folding state strongly affected the binding affinity towards the mannose-specific ConA, DC-SIGN and DC-SIGN-related (DC-SIGNR) lectins, as determined by turbidimetry and surface plasmon resonance (SPR) assays, providing direct evidence of the critical importance of controlling the secondary structures of glycopolymers for biological applications (Figure 8).

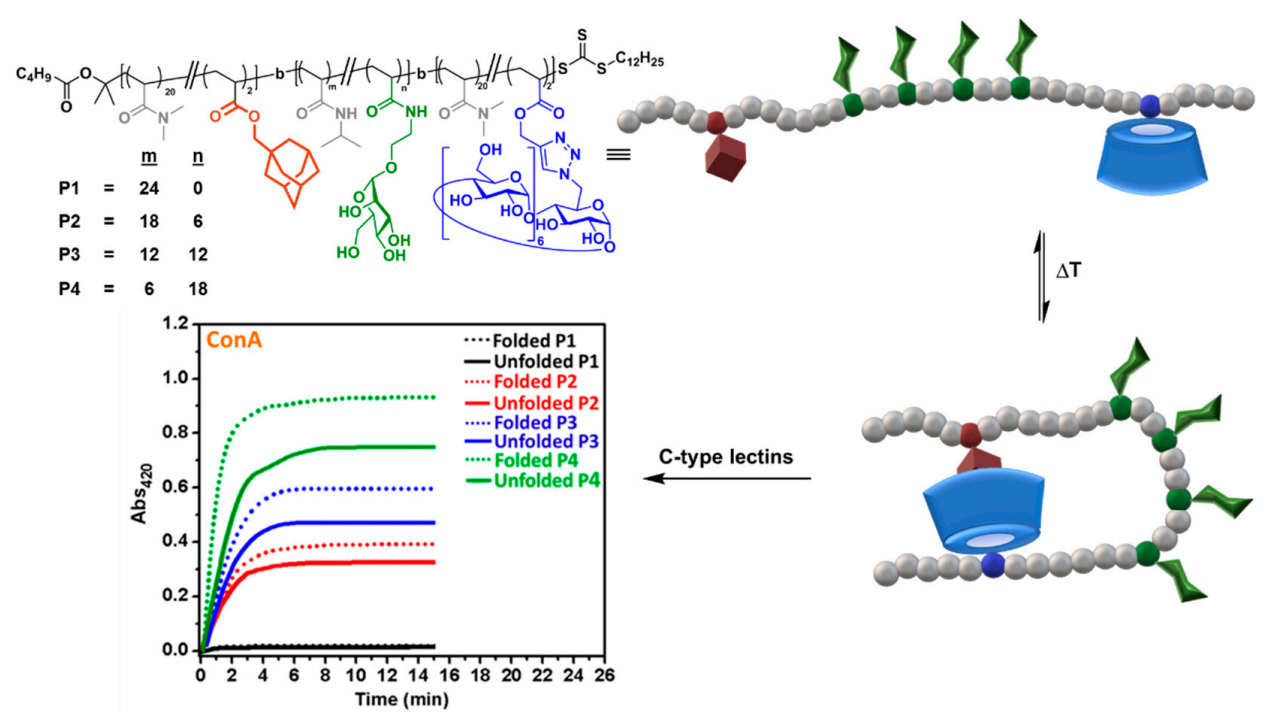

Figure 8. Triblock glycocopolymers bearing $\beta C D$ units designed by Bercer and coworkers [63] to modulate the C-type lectin binding properties through intramolecular host-guest control of the folding state. Adapted with permission from Reference [63], https://pubs.acs.org/doi/abs/10.1021/acs. biomac.8b00600. Copyright 2018 American Chemical Society. ConA, concanavalin A.

\section{GlycoCD Rotaxanation and Self-Aggregation Strategies}

Treading glycoCD "beads" onto linear polymeric "strings" affords supramolecular dynamic systems, namely polyrotaxanes (if the polymer chain bears capping end-groups) or pseudopolyrotaxanes (if the capping groups are missing), where the glycoCD components can spin around the axes of the polymer as well as move back and forth along the polymer chain. Multivalent interactions with lectin partners can thus be maximized. Pioneering work in this area was conducted by the groups of Stoddart [64], Yui [65], Sasabe [66] and Fort [67] and has already been reviewed [23]. In 2017, Gao, Chen and coworkers proposed a one-pot multicomponent synthesis of pseudopolyrotaxane-based heteroglycopolymers anchored with different sugar units and fluorescent moieties via the combination of host-guest interaction, thiol-ene and copper(I)-catalyzed click chemistry in water [68]. The interest in multivalent (nano)systems exposing more than just a single type of saccharide motif has greatly increased in the last years after the publication of a cumulative number of reports describing synergistic effects in lectin binding, a phenomenon termed heterocluster effect [69-75]. Differently from earlier work, here, the glycoCD elements are generated in situ: mono(C-6)-azido and mono(C-6)-thio $\beta C D$ are combined with propargyl-armed mannose and $\mathrm{N}$-acryloylglucosamine derivatives in the presence of linear chain polypropylene glycol (PPG) and $\mathrm{Cu}(\mathrm{I})$ [68]. In this manner, the conjugation reactions and the host-guest processes take place simultaneously. The authors additionally prepared the analogous heteroglycopolyrotaxanes from pre-synthesized mannosyl- $\beta C D$ and glucosamine- $\beta C D$ conjugates, using in this case $O$-acryloyl-terminated PPG that undergoes thiol-ene coupling with mono(C-6)-thio $\beta C D$. ConA binding studies and aggregation experiments with Escherichia coli, known to expose the mannose biding lectin FimH in the type 1 fimbriae, evidenced the existence of symbiotic relationships ascribable to the heterocluster effect (Figure 9). 


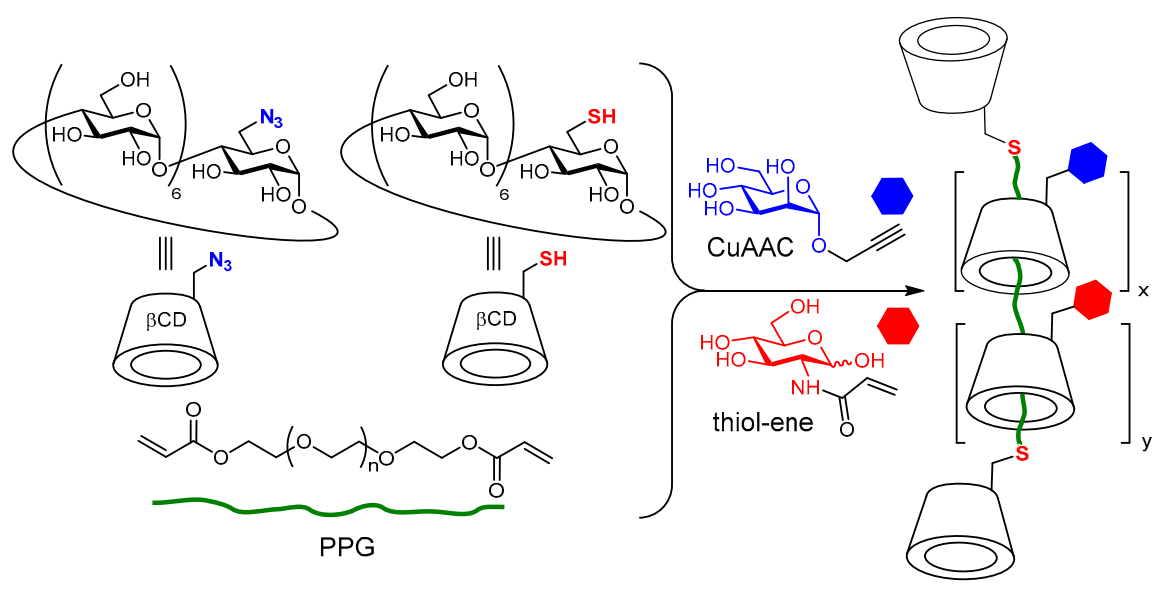

Figure 9. One-pot multicomponent synthesis of polyrotaxane-based heteroglycopolymers developed by Gao, Chen and coworkers [68]. CuAAC, copper(II) azide-alkyne cycloaddition; PPG, polypropylene glycol.

Jia, Ren and coworkers reported an alternative post-functionalization strategy for glycopolyrotaxane synthesis, whereby $\alpha \mathrm{CD}$ was first threaded onto $p$-nitrophenyl carbonate-ended PEG chains followed by amide-forming capping with an amine-equipped bile acid derivative. The primary positions of the $\alpha \mathrm{CD}$ beads were next succinylated and the resulting interlocked poly(carboxylic acid) was subsequently conjugated with glucosamine. The glyco- $\alpha \mathrm{CD} / \mathrm{PEG}$ polyrotaxane thus obtained formed micelles in aqueous solution that exhibited remarkable doxorubicin-loading capabilities and selectively delivered the drug to mouse $4 \mathrm{~T} 1$ breast cancer cells and not to normal NIH3T3 cells [76] (Figure 10).
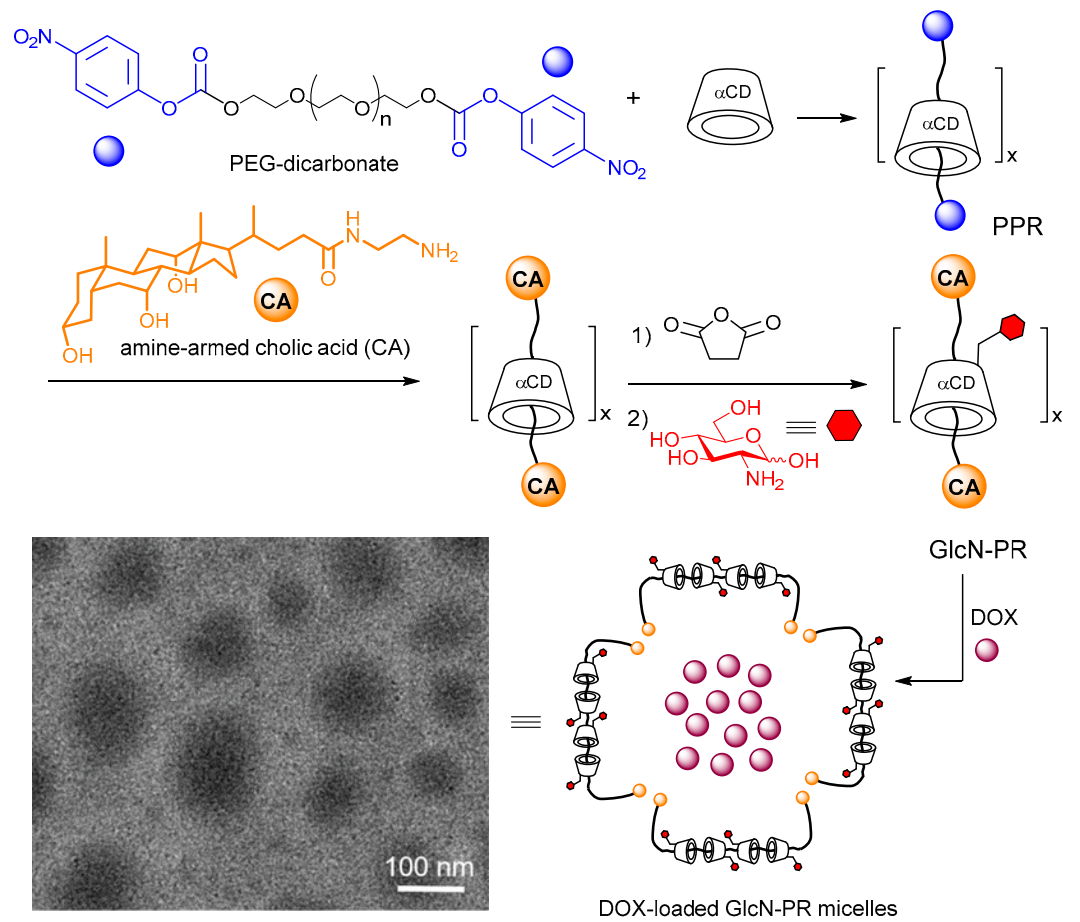

Figure 10. Polyrotaxane-based glycopolymers developed by Jia, Ren and coworkers [76] and a schematic representation of their self-assembly into doxorubicin-loaded micelles for the targeted delivery of the drug to tumor cells. A representative transmission electron microscopy (TEM) micrograph of the later is also shown. Adapted with permission from Reference [76]. Copyright 2019 WILEY-VCH. PEG, polyethylene glycol; PPR, pseudo(polyrotaxane); GlcN-PR, 2-amino-2-deoxy- $\beta$-D-glucopyranose-appended $\alpha \mathrm{CD}$-based polyrotaxane; DOX, doxorubicin. 
CD derivatives bearing substituents that fit the cyclooligosaccharide cavity can undergo self-inclusion or intermolecular inclusion phenomena. If reciprocal, the second process affords supramolecular homodimers, whereas if it propagates, poly-pseudo[2]rotaxane-type supramolecular oligomers can form [77-79]. Vargas-Berenguel and coworkers explored the possibility of exploiting this approach for the assembly of functional glycosystems from $\beta C D$ precursors randomly substituted at the primary positions with mannosyl or $\alpha(1 \rightarrow 2)$-mannobiosyl residues (through CuAAC click conjugation) and 4-nitro-3-(trifluoromethyl)aniline moieties (through propylenediamine bridging) [80]. The latter is a nitric oxide (NO) photodonor (NOPD) that offers the possibility to deliver NO with high spatiotemporal control, thus favoring reducing side-effects and improving therapeutic outputs, e.g., for antimicrobial, antioxidant or anticancer applications. From hydrodynamic diameters $\left(\mathrm{d}_{\mathrm{H}}\right)$ measurements, the authors concluded that head-to-head dimeric species are predominant in aqueous solution, which translates into a two-fold increase in valency and a significant multivalent effect, as determined for ConA lectin binding. The dimers also displayed increased NO photodelivery efficiency upon irradiation with visible light, which supports their potential for targeted NO-based therapies (Figure 11).

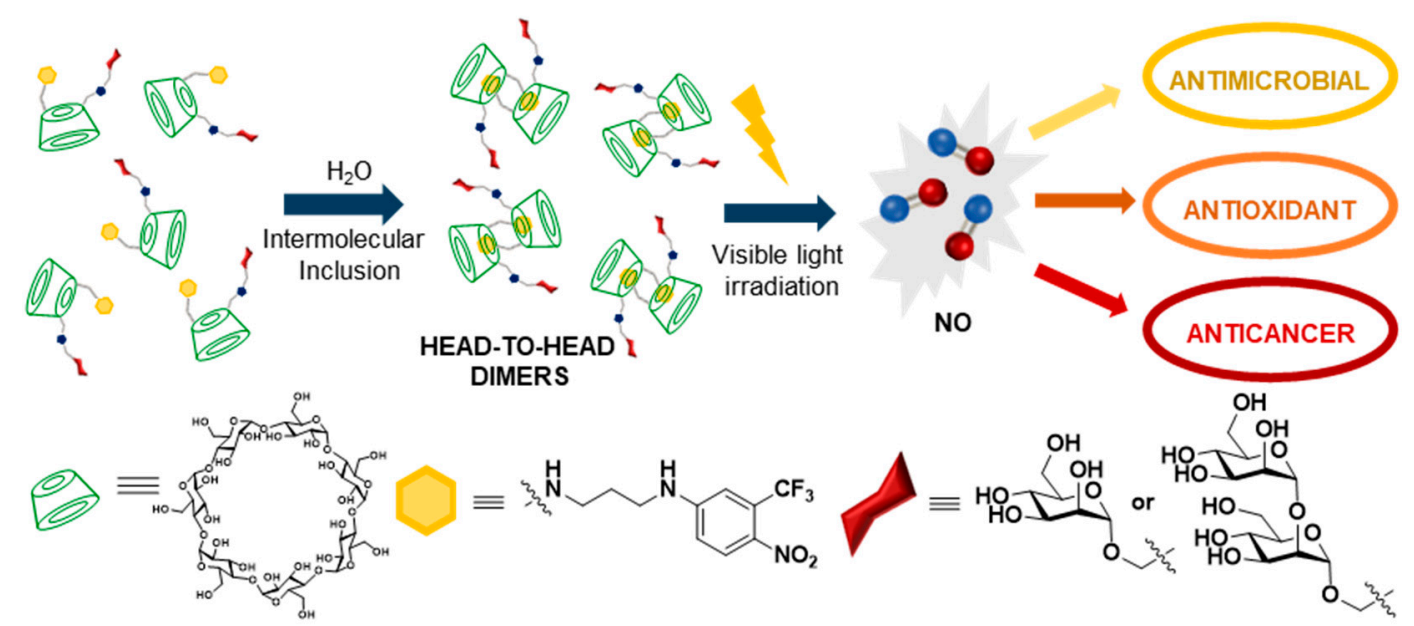

Figure 11. Structures and schematic representation of the functional supramolecular glycosystems developed by Vargas-Berenguel and coworkers for targeted nitric oxide-based therapies [80]. NO, nitric oxide.

\section{Biomacromolecule-Templated Formation of Functional GlycoCD Nanoassemblies}

Besides polymers, many kinds of biomolecules, including proteins and nucleic acids, also bear great potential as building blocks to form hierarchical glyconanomaterials by controllable co-assembly with glycocyclodextrin partners. In order to achieve specific functionalities, a key issue is to effectively adjust the supramolecular interactions to form the desired structures. Differently from synthetic polymers, for which the incorporation of ad hoc motifs enabling multiple host-guest phenomena can be easily implemented, programming cyclodextrin-biomolecule associations requires emulating biomimetic mechanisms relying primarily in hydrogen bonding, electrostatic, polar, hydrophobic or ligand-receptor interactions [81]. Such an approach implies the incorporation of functional elements in the CD platform, allowing those processes to occur in a predetermined manner. Eventually, the CD macro-ring can be additionally engaged in second-level supramolecular events, offering excellent opportunities for finely tuning glyconanomaterial properties. Chen and coworkers [82] smartly illustrated this concept by exploiting the ability of the mannosylated $\beta C D$ derivative $\beta C D-M a n$ to crosslink ConA and adamantane-equipped poly(ethylene glycol) chains (Ada-PEG). The ability of the $\beta C D$ cavity to host the adamantane fragment with high affinity was found to be unaffected by the recognition of the sugar ligand by the lectin. Similarly, the behavior of mannose as a ligand in biological interactions was not altered by the presence of the supramolecular host, confirming the dual molecular recognition abilities 
of $\beta C D$-Man. ConA is a tetramer at neutral $\mathrm{pH}$, each monomer bearing a single mannose binding site. Given that the binding constant for the mannose-ConA association is rather weak $\left(K_{\mathrm{a}} \approx 10^{3} \mathrm{M}^{-1}\right)$, unless multivalently presented, the number of binding sites occupied in $\beta C D$-Man/Ada-PEG/ConA supra-conjugates was strongly dependent on the concentration of the constitutive building blocks, which was used by the authors to regulate the assembly behavior. A third supramolecular level was next implemented by adding $\alpha \mathrm{CD}$, which is known to form pseudo-polyrotaxanes upon threading in PEG chains, thereby driving further assembly of the conjugates into large objects. By modulating the different supramolecular phenomena at play, diverse nanoobjects, from nanoparticles to high-strength hydrogel, could be engineered (Figure 12).

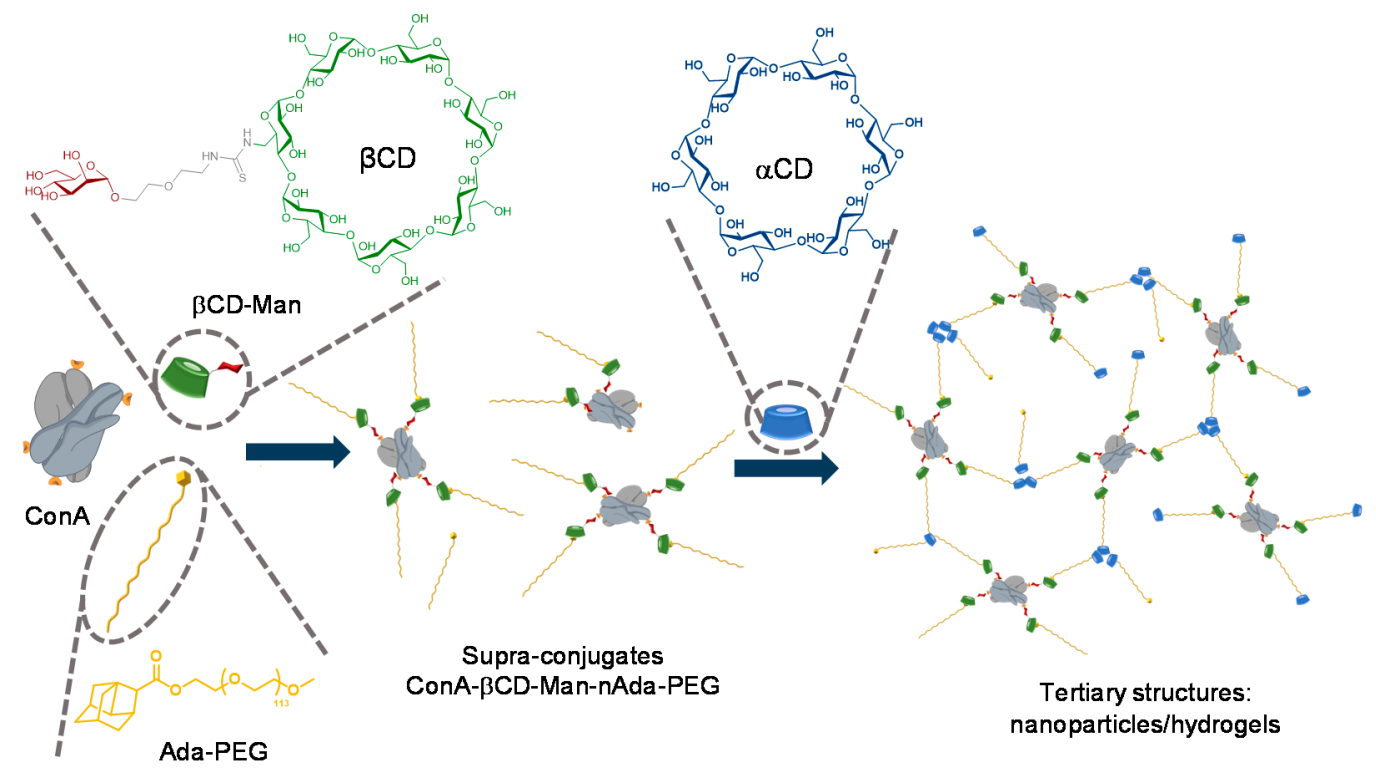

Figure 12. Molecular structures and schematic illustrations of the mannosylated $\beta C D$ derivative $\beta C D-M a n$, the adamantane-equipped poly(ethylene glycol) derivative Ada-PEG, concanavalin A (ConA) and $\alpha \mathrm{CD}$, and of their combination to obtain supramolecular nanoparticles and hydrogels, as reported by Chen and coworkers [82]. CD, cyclodextrin; Man. Mannose; Ada-PEG, adamantane-equipped poly(ethylene glycol), ConA, concanavalin A.

Nucleic acid molecules are polyanions in aqueous solution and thus electrostatically interact with various types of polycations. The resulting polyelectrolyte complexes have found application in gene delivery technology [83,84]. Most nonviral nucleid acid carriers (vectors) reported are polymeric, conformationally undefined or complex nanoparticulate materials [85]. In the last decade, however, multivalent polycations based on molecular systems emerged as a promising alternative [86-96]. Polycationic cyclodextrins have become the iconic representatives in this category [5,97-104]. The efficiency in compacting nucleic acids into nanocomplexes (so-called CDplexes) capable of mediating cell entry and subsequent expression of the nucleic acid anticipated activity (transfection) was significantly enhanced for prototypes that can additionally establish cyclodextrin-cyclodextrin interactions through either hydrophobic [105-133], host-guest [79,134] or aromatic-aromatic contacts [135-146]. As a logical extension, the formulation of CDplexes exposing biorecognizable ligands for the purpose of site-specific gene delivery has been proposed [147-155], including the elaboration of carbohydrate decorated CDplexes (glycoCDplexes) conceived for cell receptor glycotargeting [3]. In a first attempt, García Fernández and coworkers prepared three-component supramolecular assemblies from a multi-head/multi-tail polycationic amphiphilic CD displaying 14 primary amino groups (paCD- $\left.\mathrm{N}_{14}\right)$, a glycoamphiphilic $\mathrm{CD}(\mathrm{GaCD})$ bearing mannosyl residues at the seven primary $\beta C D$ positions (GaCD-Man ${ }_{7}$ ) and a luciferase-encoding plasmid DNA (pDNA; pTG11236, $5739 \mathrm{bp}$ ) (Figure 13) [156]. paCD-N ${ }_{14}$ was known to form CDplexes that efficiently mediated transfection in 
several cell lines. Disappointingly, the presence of the neutral GaCD-Man 7 component, even at low (5-10\%) proportion, resulted in nanoparticles that failed to protect pDNA from the environment. The authors ascribed the negative result to a mismatching effect of segregated cationic and neutral microdomains upon pDNA templation, leading to CDplex destabilization, and proposed a new vector design to overcome this issue: polycationic glycoamphiphilic CDs (pGaCDs) presenting regular arrangements of glyco-cationic moieties. To test this conception, a compound bearing the cationic centers (seven) and the mannosyl moieties (seven) at distinct branches in a perfectly monodisperse $C_{7}$ symmetrical dendroidal architecture, namely pGaCD-N $7 \mathrm{Man}_{7}$, was synthesized. Gratifyingly, pGaCD-N $\mathrm{Man}_{7}$ formed homogeneous distributions of small-size glycoCDplexes with pDNA $(80 \pm 35 \mathrm{~nm}$, as determined by DLS) that fully prevented the nucleic acid cargo from degradation by nucleases. TEM micrographs revealed a snake-like ultrastructure probably arising from alternating packing of electron-dense (pDNA strains) and electron-deficient (lamellar pGaCD arrangements) regions (Figure 13). The mannosylated nanocomplexes efficiently recognized the mannose-specific lectins ConA and human macrophage mannose receptor (hMMR), as ascertained by the enzyme-linked lectin assay (ELLA) [157-160]. Most notably, they promoted specific internalization and transfection in RAW264.7 (mouse leukemic monocyte macrophage) cells, known to express mannose receptors involved in receptor-mediated endocytosis at the cytoplasmic membrane.
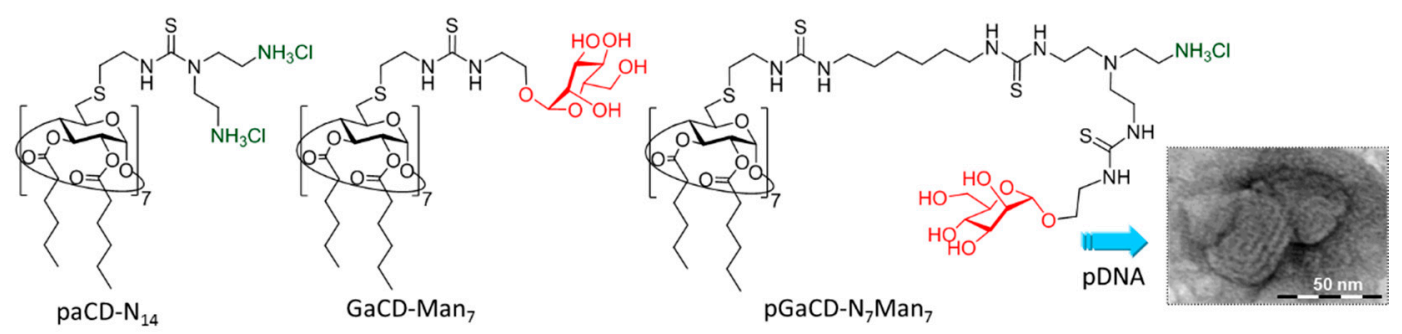

Figure 13. Structures of the polycationic amphiphilic $\beta C D$ derivative paCD- $\mathrm{N}_{14}$ (14 cationizable primary amines), the glycoamphiphilic $\beta C D$ derivative GaCD-Man 7 (neutral; 7 mannosyl residues) and the polycationic glycoamphiphilic $\beta C D$ derivative $(7$ cationizable primary amines and 7 mannosyl residues) reported by García Fernández and coworkers [156]. A representative image at high magnification of the CDplexes obtained from the latter and the luciferase-encoding plasmid DNA (pDNA) pTG11236 (5739 bp) is also shown. Adapted with permission from Reference [156]. Copyright 2011 Elsevier.

GlycoCDplexes formed upon nucleic acid templation of $\mathrm{pGaCDs}$ shall expose multiple copies of the saccharide motif at the periphery. In other words, they will bear intrinsic multivalency, an important requisite for the recognition of functional glyconano(bio)materials by cognate lectins [161-163]. In principle, the ligand surface density will increase with the pGaCD valency, which would be expected to translate into enhanced lectin binding avidities. Yet, the presence of the sugar residues in the vector architecture may negatively affect the nucleic acid complexation/nanocondensation process by shielding the cationic centers or by decreasing their number (e.g., if their incorporation involves cancelling pre-existing amino groups). Harmonizing nucleic acid and lectin binding properties through careful pGaCD design is therefore essential in the context of nucleic acid glycotargeting strategies. Di Giorgio, Benito and coworkers addressed this issue for the particular case of macrophage-directed gene delivery [164]. The authors selected two lead paCDs featuring 14 primary and 7 tertiary amino groups at the primary face and 14 hexanoyl tails at the secondary rim, but differing in either the presence of 1,2,3-triazol (paCD-triazol; Figure 14a) or thiourea linkers (paCD-thiourea; Figure 14b). Both the paCD-triazol and paCD-thiourea precursors were reacted with 2-isothiocyanatoethyl $\alpha$-D-mannopyranoside (ManEt-NCS; Figure 14c) in variable proportions, in order to achieve conjugates with 5\%,15\%,30\% and 50\% of the primary amino groups transformed into mannopyranosylethylthioureido segments. As expected, the capability to neutralize and fully protect pDNA decreased with the mannosylation degree. Conversely, glycoCDplexes formulated 
with the more heavily mannosylated vectors showed higher stability in saline medium (150 mM), probably by endowing the nanoparticles with a thicker hydration shell that prevents non-specific aggregation phenomena. Most importantly, mannosylated CDplexes exhibited remarkably alveolar peritoneal macrophage (mice) adhesion abilities. In vitro experiments using MMR-positive mouse leukemic monocyte macrophages (RAW264.7), MMR-devoid embryonic murine hepatocytes (BNL-CL2) and African green monkey kidney fibroblasts (COS-7) confirmed that mannosylation results in notable transfection selectivity enhancements towards the macrophage cell line (Figure 14d). Taking all data together, $30 \%$ and $15 \%$ mannosyl loadings were determined to be optimal in the triazol and thiourea series respectively, to achieve glycoCDplexes with high macrophage transfection levels and minimal off-target transfection in other cells.
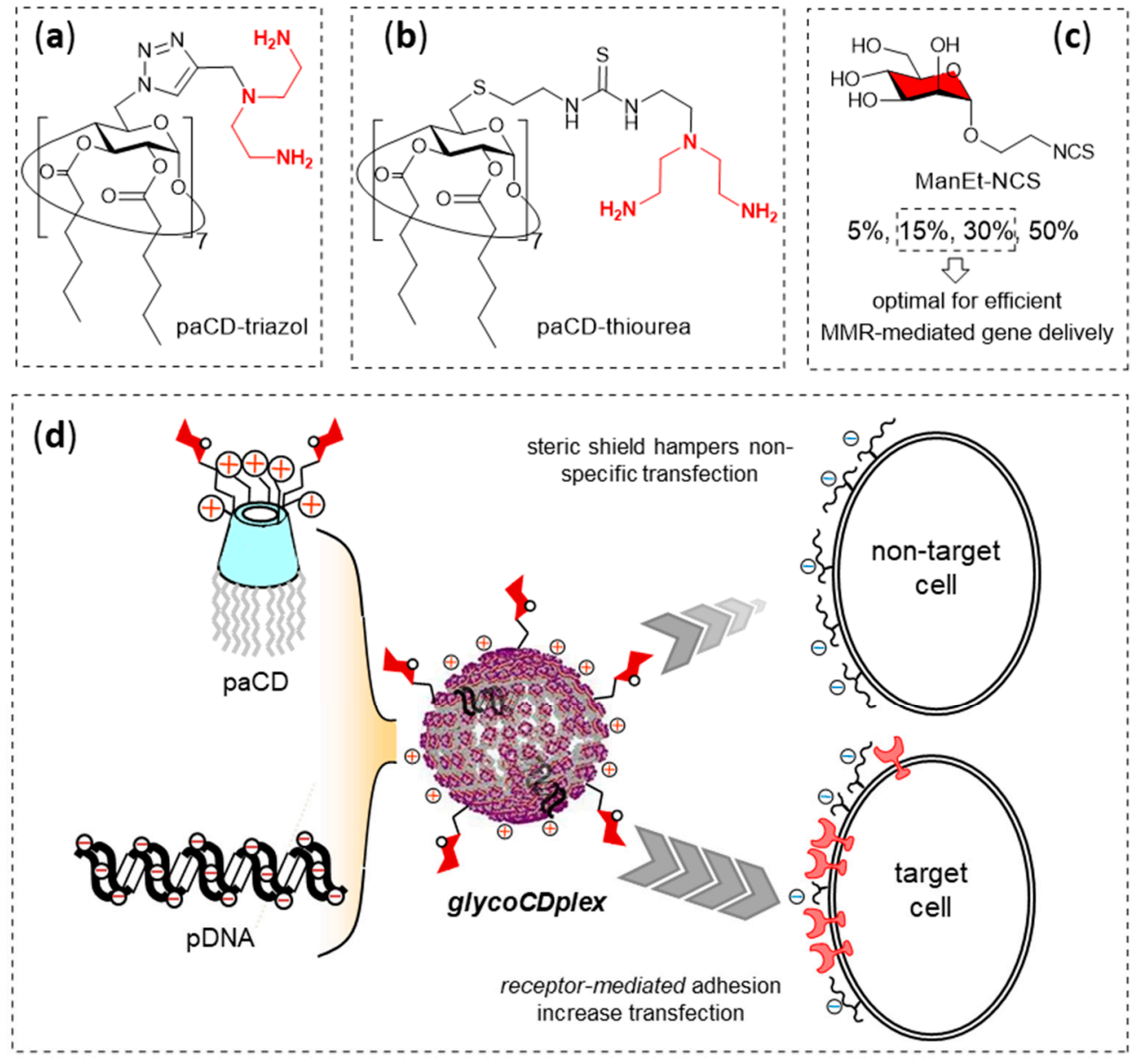

Figure 14. Structures of the paCD-triazol (a), paCD-thiourea (b) and ManEt-NCS (c) precursors used by Di Giorgio, Benito and coworkers [164] to prepare $\mathrm{pGaCDs}$ with variable proportions of mannosyl motifs, and a schematic representation of their co-assembly with pDNA to form glycoCDplexes that selectively promoted receptor (MMR)-mediated transfection of the targeted cells (macrophages) (d). Adapted with permission from Reference [164]. Copyright 2015 Royal Society of Chemistry. paCD, polycationic amphiphilic cyclodextrin; Man, mannose; $\mathrm{pGaCDs}$, polycationinc glycoamphiphlic cyclodextrins; MMR, macrophage mannose receptor.

O'Driscoll and coworkers [165] prepared pDNA-templated glycoCDplexes combining a paCD [166] and a galactosylated or lactosylated neutral amphiphilic CD [51] in 95:5 (w/w) relative proportion, in view of targeting the galactose/galactosamine-specific asialoglycoprotein receptor (ASGPR) at the surface of parenchymal hepatocytes (Figure 15). The authors monitored the transfection efficiency in human cellular ASGPR-positive hepatocarcinoma Hep-G2 cells and found that statistically significant enhancements, as compared with non-targeted formulations, were achieved only 
when the helper lipid 1,2-dioleoyl-sn-glycero-3-phosphoethanolamine (DOPE) was included in the formulation. Confocal microscopy studies revealed that the incorporation of DOPE in targeted systems did not lead to higher cell uptakes of galactosylated as compared with non-galactosylated nanocomplexes but resulted in a much faster endosomal escape of the glycotargeted nanocomplexes upon receptor-mediated endocytosis.

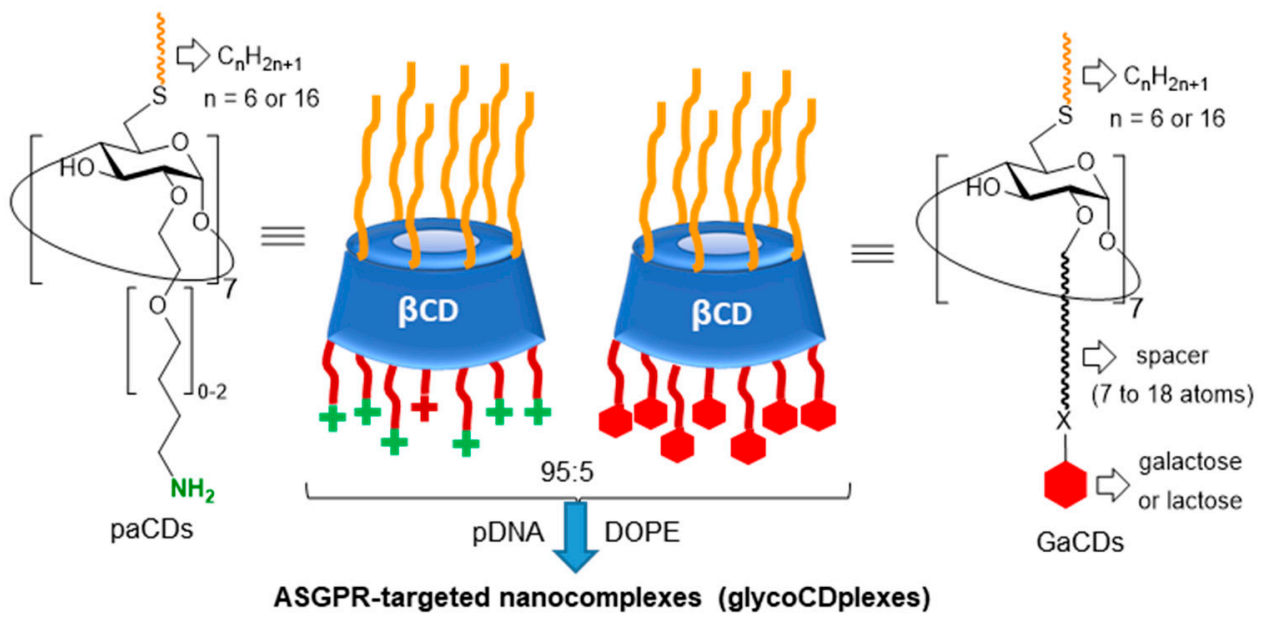

Figure 15. Structures of the polycationic amphiphilic CDs (paCDs) and glycoamphiphilic CDs (GaCDs) used by O'Driscoll and coworkers [165] for the formulation of pDNA-templated nanocomplexes (glycoCDplexes) targeting the asialoglycoprotein receptor (ASGPR). DOPE, 1,2-dioleoyl-sn-glycero-3-phosphoethanolamine.

To avoid the need for using DOPE-containing polyformulations and the high synthetic cost associated to fully regular, diasteremerically pure $\mathrm{pGaCD}$ vectors, Rejman and coworkers proposed an alternative strategy consisting in the statistic conjugation of paCDs with glycodendrons [167]. Indeed, CD-glycodendrimer constructs have shown high promise for lectin-targeted, site-specific drug delivery $[35,158,168,169]$. The notion behind this is that biologically useful multivalent presentations can be achieved in this manner with no need for sacrificing many cationic centers in the conjugation step, thus preserving the nucleic acid nanocomplexation properties intact. As a proof of concept, the authors incorporated a trivalent galactosyl dendron, a good ligand for the ASGPR, onto a paCD that exhibited good gene vector properties, in $10 \%$ or $12 \%$ proportions relative to the peripheral amines. Both conjugates were able to complex a green fluorescent protein (GFP)-encoding pDNA, but puzzlingly, the resulting glycoCDplexes turned out to be inefficient at transfecting Hep-G2 cells. Specific tests were conducted to ascertain at what stage in the process from uptake to translation the pDNA-glyoCDplexes failed. Neither internalization nor endosomal scape or pDNA release were found to be problematic, with the ensemble of results suggesting that translocation of the pDNA into the nucleus represented the main obstacle. Indeed, replacing pDNA into messenger RNA (mRNA), which does not need to reach the nucleus to express the encoded protein, resulted in outstandingly high transfection levels, much higher than those achieved with the commercial polymeric vector poly(ethyleneimine)-hepatocyte (jetPEI-Hepatocyte) (Figure 16). Blocking the ASGPR with anti-ASGPR antibodies cancelled transfection, demonstrating that the galactosyl-CDplexes enter the cells through ASGPR-mediated endocytosis.

Jiménez Blanco, Di Giorgio and coworkers proposed an alternative $\mathrm{pGaCD}$ vector design that displayed aminoglucosyl units attached at all primary positions of the per $(\mathrm{O}-2, \mathrm{O}-3)$-hexanoylated $\beta \mathrm{CD}$ scaffold, instead of bearing amine groups and sugar ligands at separate branches [170]. They encountered that the self-assembling and transfection aptitude of these compounds were very sensitive to the aminoglycoside structure: 6-amino-6-deoxy and 2-amino-2-deoxy- $\beta$-D-glucopyranosylthioureido conjugates readily formed glycoCDplexes (75-100 nm hydrodynamic diameter) in the presence of pDNA, 
but only the first ones were efficient at promoting transfection in COS-7 cells. A homologous heptaconjugate exposing 2,6-diamino-2,6-dideoxyglucoside motifs formed a solid precipitate in the presence of pDNA and was not further pursued. Most interestingly, the 6-amino-6-deoxyglucoside pGaCD was found to selectively bind the galactose-specific lectin peanut agglutinine (PNA) and preferentially internalize BNL-CL2 hepatocytes by ASGPR-mediated endocytosis [171], highlighting this iminosugar as a dual nucleic acid/lectin receptor binder when presented in multivalent form (Figure 17).
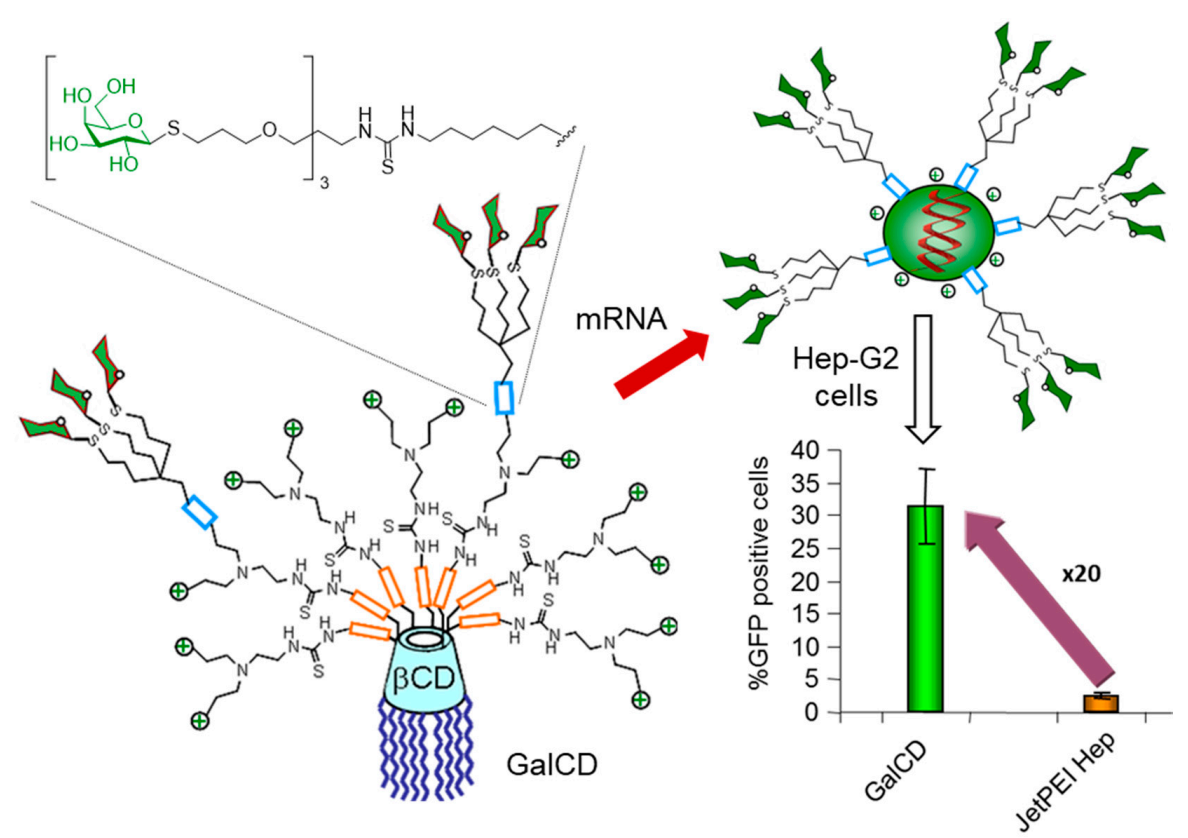

Figure 16. Schematic representation of the statistically galactosylated paCD (GalCD) vectors used by Rejman and coworkers to formulate glycoCDplexes with mRNA for the ASGPR-mediated transfection of hepatocytes [167].

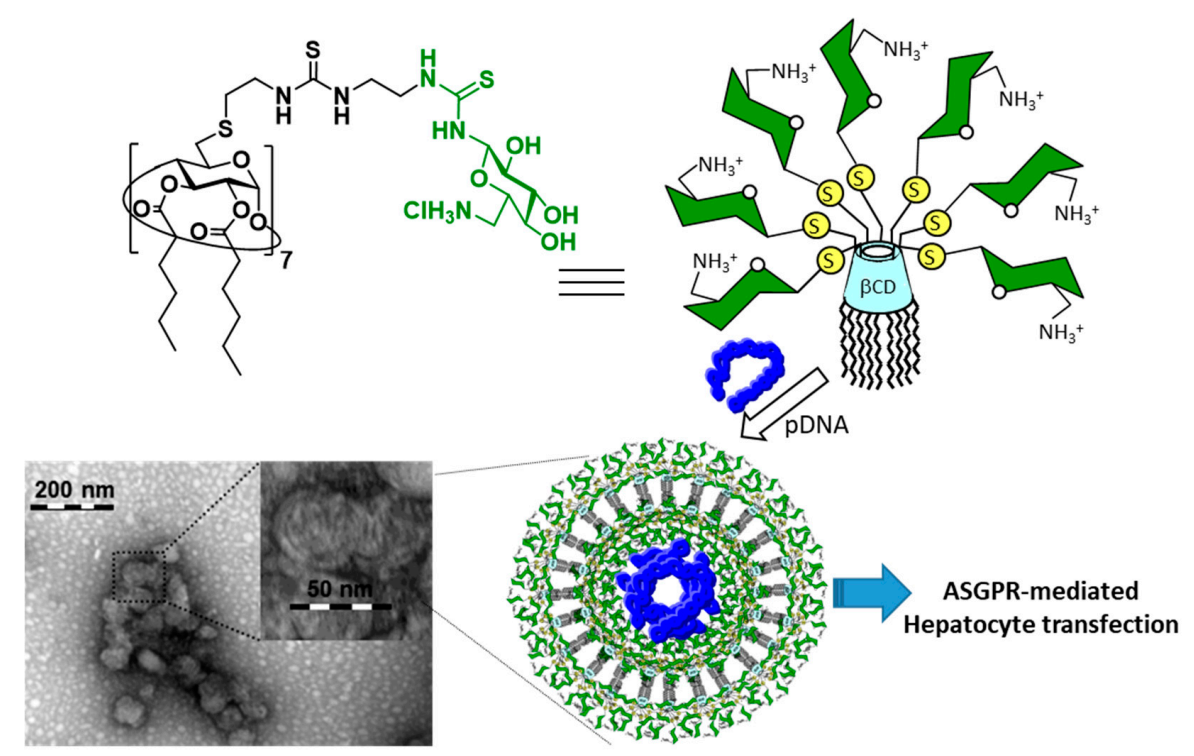

Figure 17. Structure of the 6-amino-6-deoxy $\beta$-D-glucopyranosylthioureido/ $\beta C D$ conjugate prepared by Jiménez Blanco, Di Giorgio and coworkers, and an illustration of their co-assembly with pDNA to form nanocomplexes that promoted ASGPR-mediated transfection of hepatocytes [170,171]. A representative TEM micrograph of the nanocomplexes is also shown. Adapted with permission from Reference [170]. Copyright Centre National de la Recherche Scientifique (CNRS) and Royal Society of Chemistry. 
Uekama, Arima and coworkers discovered that poly(amidoamine) (PAMAM) dendrimers functionalized with $\alpha \mathrm{CD}(\alpha \mathrm{CDEs})$ formed nanocomplexes with nucleic acids (dendriplexes) with very high transfection capabilities. The increase in efficiency at delivering the cargo to target cells was ascribed to an enhanced endosomal escaping ability through the cooperative action of a proton sponge effect of PAMAM dendrimer and the inclusion ability of $\alpha \mathrm{CD}$ towards phospholipids in endosomes [172,173]. A degree of substitution (DS) of 2.4 was revealed as optimal. By appending different glycoligands to remaining peripheral amine groups in the dendrimer, they engineered glyco- $\alpha$ CDEs that in the presence of $\mathrm{pDNA}$ or siRNA, formed glycodendriplexes specifically targeting complementary lectin receptors. Early work from this group has already been reviewed [97]. Recent versions of the general prototype include lactosyl- and mannosyl- $\alpha$ CDEs (generation 3, G3) for specific siRNA delivery to hepatocytes [174] and antigen-presenting cells (APCs) [175], respectively. The first ones were also decorated with PEG-chains (PEG-L $\alpha$ CD) and have shown promise in transthyretin-related (TTR) amyloidosis therapy [176], whereas the second (Man-S- $\alpha \mathrm{CD}$ ) showed potential for the treatment of fulminant hepatitis [177] (Figure 18).

(a)

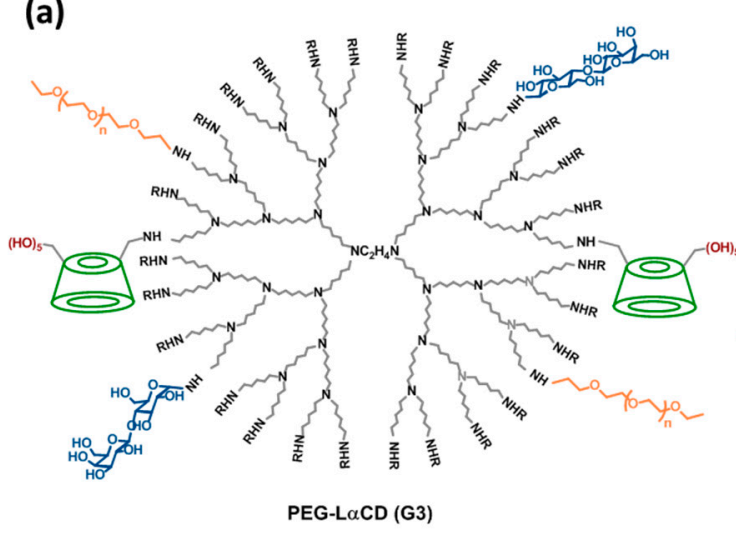

(b)

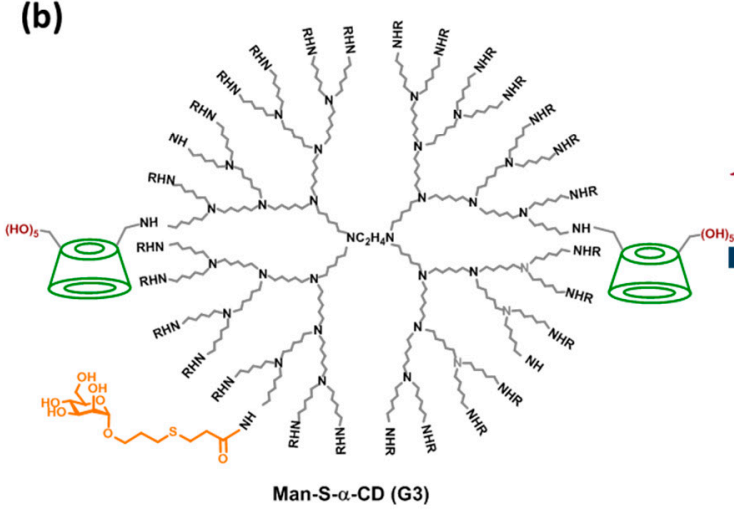

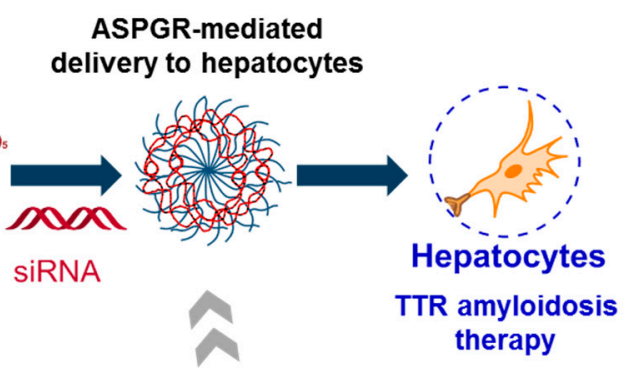

CD-coated

glycodendriplexes

SiRnA

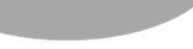

$\Rightarrow 8$

MR-mediated delivery to APCs

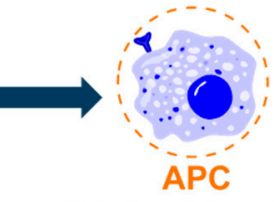

Fulminant hepatitis therapy

Figure 18. Structures of the lactosylated (a) and thiomannosylated (b) $\alpha \mathrm{CD}$-coated glycodendrimers prepared by Arima and coworkers and a schematic representation of their co-assembly with siRNA to form dendriplexes targeted to hepatocytes or antigen-presenting cells (APCs) respectively, for the treatment of transthyretin-related (TTR) amyloidosis [176] or fulminant hepatitis [177].

\section{Host-Guest Mediated Glyco-Coating of Self-Assembled CD Nanoparticles}

The micellar or vesicular supramolecular materials assembled from amphiphilic CD molecules are intrinsically multicompartmental. Provided that access to the cavity of the individual cyclooligosaccharides at the surface of the aggregates is not blocked, they can be exploited as anchoring centers for functional moieties equipped with appropriate guest motifs. Based on these grounds, Ravoo and coworkers developed a host-guest approach to glycosylate the external surface 
of cyclodextrin vesicles (CDVs) [178,179]. A main advantage is that given the dynamic character of the interactions at play, the resulting glyco-CDVs better imitate the fluidity of the cell membrane as compared with nanosystems built from covalent glycoCDs. The vesicular nanoplatform was obtained from $C D$ precursors where all primary hydroxyls have been replaced by dodecylthio tails and some of the secondary hydroxyls, mainly O-2-positions, are etherified with ethylene carbonate. The latter reaction results in the installation of oligo(ethylenglycol) chains, which on average are diethylenglycol residues, thereby creating a hydrophilic domain [180]. In spite of bearing a certain polydispersity, the self-assembled CDVs (average hydrodynamic diameter $\approx 120-150 \mathrm{~nm}$ ) engineered from these CDs are very stable and behave as host membranes [181]. $\beta C D$-based CDVs and Ad-armed glycoconjugates have been most often employed to formulate glyco-CDVs [182], but other high-affinity guest motifs have also been explored, such as diamantane or triamantane derivatives. Interestingly, mannopyranosyl glycosides bearing the later diamandoids were efficiently fixed onto $\beta C D$ as well as $\gamma C D C D V s$, affording multivalent mannosyl-CDVs capable of recognizing mannose-specific receptors, as illustrated by their ability to agglutinate ConA lectin [183]. In the case of $\beta C D C D V s$, using bipodal adamantane branches as anchoring elements has proven particularly convenient, enabling the efficient conjugation with single mannosyl ligands but also with up to octavalent mannosyl glycodendrons. Such high-valent mannosyl-CDVs (Man-CDVs) proved very efficient at disturbing the interaction between a FimH lectin-expressing uropathogenic E. coli strain (ORN178) and the human uroepithelial cell line RT-4 [184] (Figure 19).

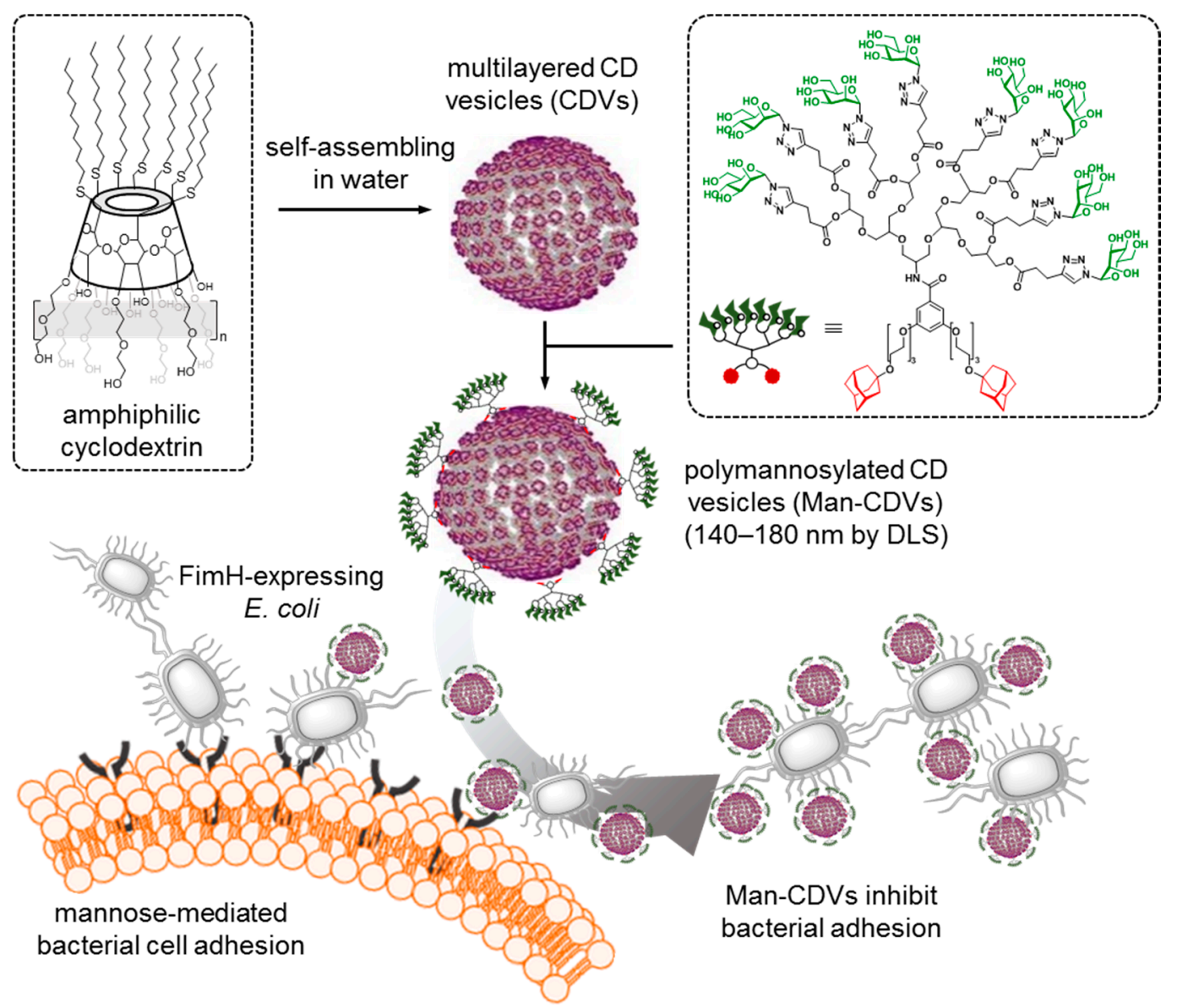

Figure 19. Illustration of the strategy developed by Ravoo and coworkers for the preparation of self-assembled CD-based vesicles (CDVs), their coating with mannosyl dendrons through host-guest interactions and the potential of the resulting Man-CDVs in anti-adhesive therapy against uropathogenic FimH-expressing E. coli [184]. 
Sansone, Casnati, García Fernández, Ceña and coworkers have elaborated self-assembled CD nanospheres (NSs) and nanocapsules (NCs) from CD-calixarene heterodimers [185,186]. The basic prototype consists in a $\beta C D$ module having either hydroxyl or methyl ether groups that is connected through a single primary position to a spacer element of variable length and nature, which also joins a calix[4]arene (calix[4]) component. The latter bear aliphatic chains etherifying the four phenolic oxygens at the lower rim, making it strongly hydrophobic. Upon nanoprecipitation in water in the absence or in the presence of a pharmaceutically acceptable oily additive, NSs (mean diameter 10-40 nm as determined by AFM and TEM) or NCs (50-100 nm) were obtained. In the NSs, the calix[4] hydrophobic matrix is surrounded by a CD-exposing hydrophilic shell, whereas in the NCs, the core is occupied by the oily medium. Both NSs and NCs showed high loading capacity towards the anticancer drugs docetaxel, temozolomide and combretastatin A-4 and high efficiency at delivering them to different cancer cells: LNCaP and PC3 prostate cancer, MCF-7 breast cancer, glioblastoma U87, HeLa cervical cancer and HT-29 colon cancer cells. As for the CDVs discussed above, the $\beta C D$ units at the external shell can host the Ad part of glycodendron-Ad conjugates, imparting glycotargeting abilities. As a proof of concept, a trivalent mannosyl dendron was supramolecularly installed onto $\beta C D$-calix [4] NSs and the resulting glycol-NSs were shown to be specifically recognized by the MRR [187] (Figure 20).

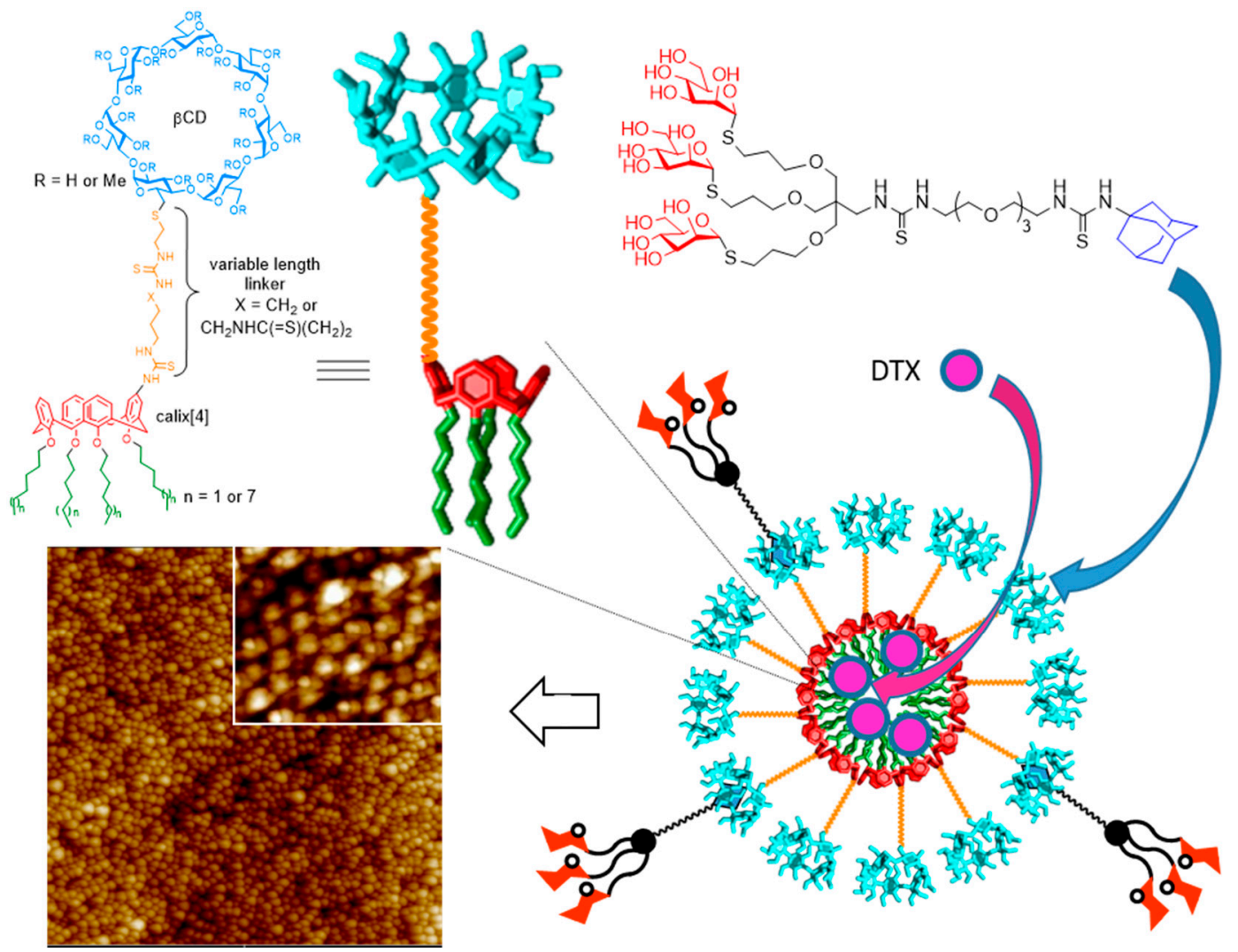

Figure 20. Illustration of the nanospheres (NSs) prepared by nanoprecipitation of $\beta C D$-calix[4]arene hybrids by Sansone, Casnati, García Fernández, Ceña and coworkers [185-187], their loading with anticancer drugs (e.g., docetaxel, DTX) and their host-guest decoration with glycoligands for targeted delivery. A representative tapping-mode atom force microscopy (AFM) image of the NSs $(5 \times 5 \mu \mathrm{M}$; insert $0.7 \times 0.7 \mu \mathrm{M})$ is also shown. Adapted with permission from Reference [187]. Copyright Royal Society of Chemistry.

\section{Functional Glyconanoparticles through CD-Mediated Glyco-Coating Strategies}

Surface decoration with cyclodextrins is a general strategy to enhance the drug loading capabilities of nanocarriers and/or to supramolecularly anchor functional components for, e.g., site-specific delivery, 
visualization or sensing. The methodology is indeed analogous to that discussed above for self-assembled systems and relies in the formation of a dynamic external shell through multiple host-guest interactions between the $\mathrm{CD}$ units on the nanoparticle and bifunctional molecules consisting of a CD guest motif, a flexible tether and an outer probe moiety. If the latter is a glycoligand, the bifunctional molecules can behave as cross-linkers between the nanoparticle and specific lectins. The work reported by Samanta and Ravoo in 2014 on magnetic iron oxide $\left(\mathrm{Fe}_{3} \mathrm{O}_{4}\right.$, $\gamma-\mathrm{Fe}_{2} \mathrm{O}_{3}$ ) nanoparticles (MNPs) capped with $\beta C D$ and their use as support for selective supramolecular capture of lectins very didactically illustrates this concept [188]. The synthesis of the $\beta C D$-capped MNPs encompassed the preparation of bare MNPs by alkaline co-precipitation of $\mathrm{Fe}^{\mathrm{II}}$ and $\mathrm{Fe} \mathrm{F}^{\mathrm{III}}$ salts followed by ligand stabilization with heptakis(6-S-carboxylpropyl-6-thio- $\beta C D$ ) (CDA). The surface of the resulting CDA-modified MNPs (MNP-CDA) were next decorated with specific carbohydrates, namely mannose and lactose, by simply adding adamantane-carbohydrate conjugates to the nanoparticles. A multivalent presentation of the monosaccharide is thus generated that orthogonally cross-linked the mannose and galactose specific lectins ConA and PNA, respectively, allowing their efficient separation from mixtures of both proteins by magnetic precipitation. The pure lectins were finally detached from the ternary complexes by addition of an excess of the corresponding octyl glycoside. More recent work has shown that the reciprocal distribution of functional moieties, that is, the use of nanoparticles displaying adamantane elements in combination with biorecognizable glycoCDs, is also found as a viable alternative for lectin purification or bacterial capture $[189,190]$ (Figure 21).

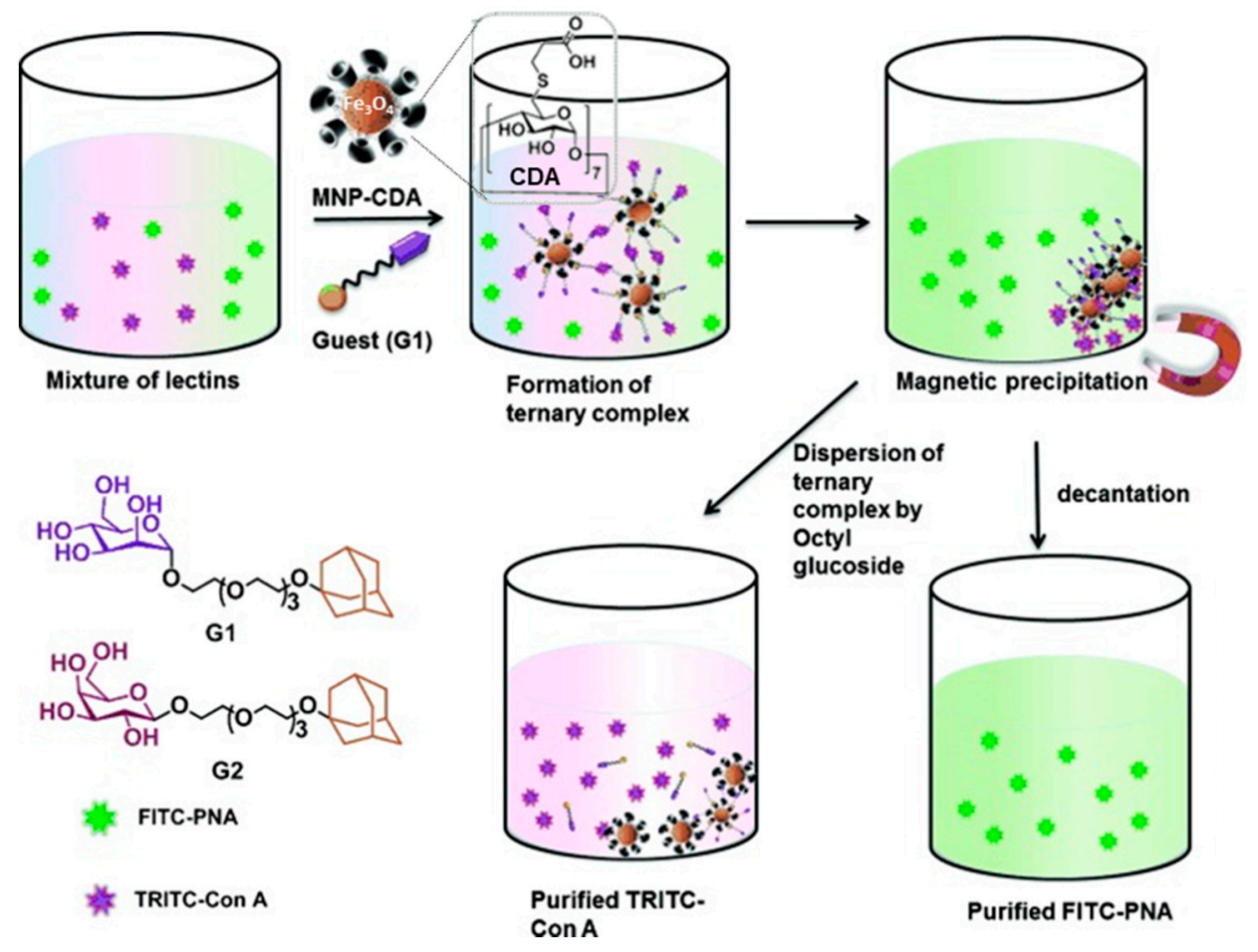

Figure 21. Illustration of the method for separation of proteins reported by Samanta and Ravoo [188] using the cross-linking and magnetic precipitation of magnetic nanoparticles modified with cyclodextrin-acid derivatives (MNP-CDA) and adamantane-armed glycoligands (G1 and G2). Reprinted with permission from Reference [188]. Copyright 2014 WILEY-VCH. FITC-PNA, fluorescein isothiocyanate-labelled peanut agglutinin; TRITC-ConA, tetramethylrhodamine-labelled concanavalin A.

The above host-guest-based approach, in whatever of the two commented modalities (CD-coated nanoparticles in combination with glycoligand-equipped cross-linkers or CD guest-coated nanoparticles in combination with glycoCDs) is very versatile and has been successfully extended to 
the non-covalent peripheral functionalization of a variety of nanometric platforms with carbohydrates for analytical or biomedical applications. Examples on record include host-guest mannose- and galactose-modified quantum dots (glyco-QDs) for the optical detection of carbohydrate-protein interactions [191,192] and mannose-decorated mesoporous silica-coated gold nanorods [193] and graphene shits [194] for E. coli bacteria agglutination and killing.

\section{Covalent Strategies to CD-Appended Glyconanomaterials}

Coating a given nanoplatform with cyclodextrins and glycan moieties, or with a glycoCD conjugate, is probably the most obvious plan to engineer nanosystems endowed with inclusion capabilities and lectin recognition properties. In 2014, Vargas-Berenguel and coworkers put this approach at work to prepare dually functionalized gold nanoparticles (AuNPs) simultaneously bearing $\beta$-cyclodextrin and lactose appendages for the development of site-specific drug delivery systems [195]. The synthesis of the $\mathrm{CD} /$ lactose-coated AuNPs was achieved from $\mathrm{CD}$ and lactose disulfide precursors by the well-known ligand exchange strategy on citrate-stabilized AuNPs. The spacer arm combined a hydrophobic portion intended to provide stability to the self-assembled monolayer on the AuNP surface and a tetraethylenglycol segment to increase the biocompatibility and the solubility in water. The presence of the cyclodextrin units made possible the loading of the anticancer drug methotrexate (MTX) by forming stable inclusion complexes, whereas the multivalent presentation of lactosyl residues imparted binding abilities towards the $\beta$-D-galactose-recognizing lectins PNA and human galectin-3 (Gal-3). Gal-3 is well-known to be overexpressed in several human tumors and is therefore a biomedically relevant target, making such hybrid AuNPs promising nanocarriers for precision anticancer therapies (Figure 22).

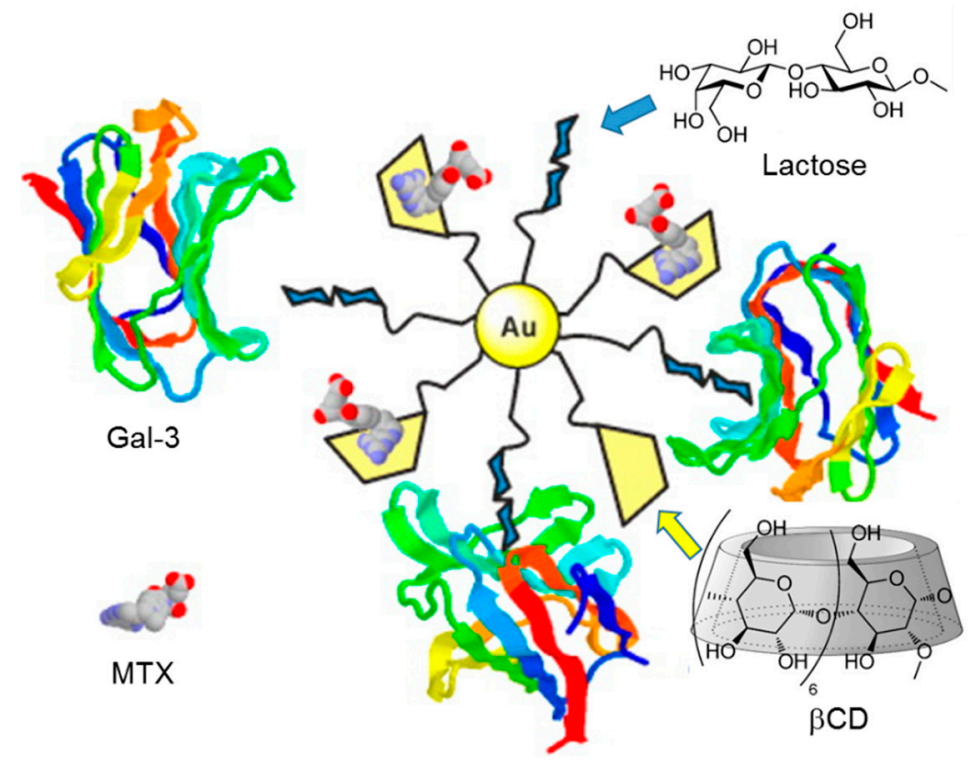

Figure 22. Illustration of the lactose- and $\beta C D$-decorated gold nanoparticles developed by Vargas-Berenguel and coworkers [195] for the selective delivery of methotrexate (MTX) to human tumors expressing galectin-3 (Gal-3). Adapted with permission from Reference [195]. Copyright 2014 American Chemical Society.

Riela, Lazzala and coworkers reported a new design of glycomaterials consisting of halloysite nanotubes (HNTs) coated with $\beta C D$-based glycoclusters [196]. Such hybrid structures were obtained through a solvent-free procedure involving two consecutive thiol-ene reactions, a first one implying heptakis[6-(tert-butyldimethylsilyl)-2-O-allyl]- $\beta$-cyclodextrin and thiol-functionalized HNTs, and a second one implying the resulting $\beta C D$-HNT adduct and 1-thioglycosides. Examples on record comprise HNTs appended with mannosyl, galactosyl and lactosyl/ $\beta C D$ glycoclusters. These hybrids combined the inclusion properties of both HNTs and $\beta C D$ and the lectin recognition abilities of the 
glycoligands. As a proof of concept, HNTs decorated with mannosylated- $\beta C D$ functional units were found to incorporate the natural anticancer drugs silibinin (Sil) and curcumin (Cur) in the HNT and the $\beta C D$ cavities respectively, while displaying high affinity towards mannose-specific lectins. The authors further confirmed the synergistic effect deriving of the co-administration of curcumin and silibinin in the 8505c thyroid cancer cell line [197] (Figure 23). The suitability of the strategy based on the attachment of CD-centered glycoclusters onto nanoparticulated platforms to improve their biocompatibility and convey lectin recognition abilities was also confirmed by Gref, Vargas-Berenguel and coworkers for the particular case of metal organic frameworks (MOFs) [198].

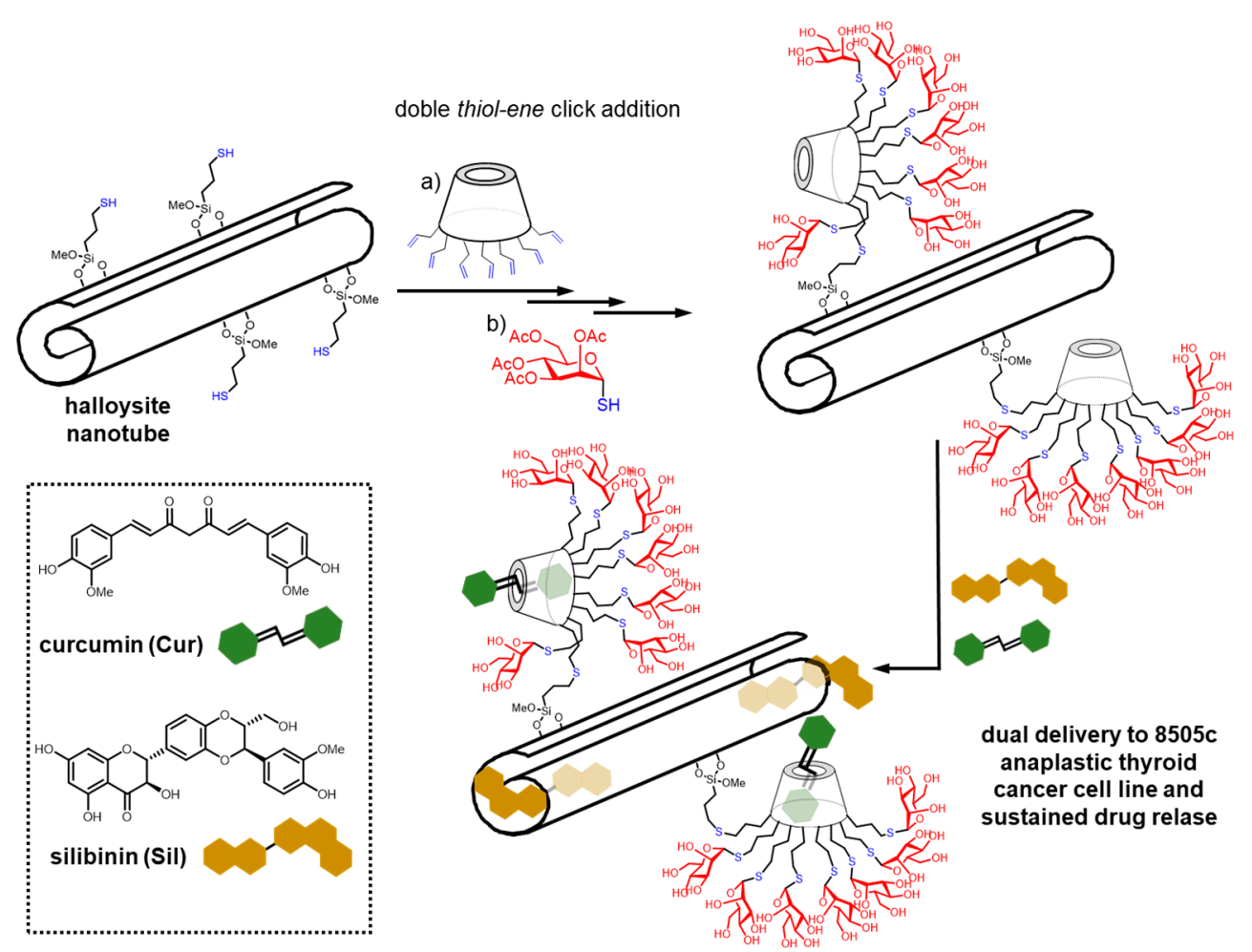

Figure 23. Structures and schematic representation of the strategy developed by Riela, Lazzala and coworkers to assemble hybrid glycoCD/halloysite nanotubes to achieve functional glyconanomaterials for the co-administration of curcumin (Cur) and silibinin (Sil) in thyroid cancer cells [196,197].

\section{Conclusions and Outlook}

The controlled amalgamation of cyclodextrin modules and glycan moieties provides a direct and effective way to create multifunctional glyconanomaterials with tailorable characteristics. The rich chemistry of CDs further allows programing their self-assembly and co-assembly properties with (bio)macromolecular partners to afford nanosystems that can be either pre- or post-conjugated with one or more types of glycoligands to hierarchically build the desired glyconanostructures. Exploiting host-guest strategies, enabled by multivalent displays of CD cavities in combination with high-affinity cavity-fitting motifs in the glycan partners, allows reaching high sophistication degrees with relatively low synthetic efforts. Alternatively, glycoCDs can be used as building blocks for the generation of supramolecular glyconanomaterials or to covalently modify appropriately functionalized nanoparticles. Whatever the strategy, the glycoligands become multivalently exposed at the surface of the final construct at densities that can be regulated, thus offering unlimited opportunities to tune their selectivity and affinity towards carbohydrate-binding receptors (lectins). Current applications focus on site-specific drug/gene delivery and protein separation and analysis. Considering the avant-garde developments in CD chemistry, glycobiology and nanotechnology, a much broader range of progress is expected in the near future from their synergistic blend, including fields as diverse as catalysis [199,200], 
bioremediation [201], sensing [202-205], diagnostics [206,207], theranostics [208,209], vaccines [210,211] or personalized medicine [212,213].

Author Contributions: J.M.B. and J.M.G.F. proposed the project. All of the authors carried out the search for reference materials and the data analysis. G.R.-B., J.M.B., C.O.M. and J.M.G.F. wrote the manuscript. C.O.M. and J.M.G.F. performed a review and the final edit. All authors have read and agreed to the published version of the manuscript.

Funding: This research was funded by the Ministerio de Ciencia, Innovación y Universidades and the Agencia Estatal de Investigación (project RTI2018-097609-B-C21), the Ministerio de Ciencia e Innovación (PID2019-105858RB-I00), and the European Regional Development Funds (FEDER-UE).

Acknowledgments: The authors acknowledge the COST action GLYCONanoPROBES (CM18132). G.R.-B. is a FPU fellow.

Conflicts of Interest: The authors declare no conflict of interest.

\section{References}

1. Tian, B.; Xiao, D.; Hei, T.; Ping, R.; Hua, S.; Liu, J. The application and prospects of cyclodextrin inclusion complexes and polymers in the food industry: A review. Polym. Int. 2020, 69, 597-603. [CrossRef]

2. Matencio, A.; Navarro-Orcajada, S.; García-Carmona, F.; López-Nicolás, J.M. Applications of cyclodextrins in food science. A review. Trends Food Sci. Technol. 2020, 104, 132-143. [CrossRef]

3. Ortiz Mellet, C.; García Fernández, J.M.; Benito, J.M. Cyclodextrins for pharmacological and biomedical applications. In Supramolecular Systems in Biomedical Fields; Schneider, H.-J., Ed.; Royal Society of Chemistry: Cambridge, UK, 2013; Chapter 5; pp. 94-139.

4. Fakayode, S.O.; Lowry, M.; Fletcher, K.A.; Huang, X.; Powe, A.M.; Warner, I.M. Cyclodextrins host-guest chemistry in analytical and environmental chemistry. Curr. Anal. Chem. 2007, 3, 171-181. [CrossRef]

5. Liu, Q.; Zhou, Y.; Lu, J.; Zhou, Y. Novel cyclodextrin-based adsorbents for removing pollutants from wastewater: A critical review. Chemosphere 2020, 241, 125043. [CrossRef]

6. Davis, M.E.; Brewster, M.E. Cyclodextrin-based pharmaceutics: Past, present and future. Nat. Rev. Drug Discov. 2004, 3, 1023-1035. [CrossRef]

7. Tian, B.; Hua, S.; Liu, J. Cyclodextrin-based delivery systems for chemotherapeutic anticancer drugs: A review. Carbohydr. Polym. 2020, 232, 115805. [CrossRef]

8. Tian, B.; Liu, Y.; Liu, J. Cyclodextrin as a magic switch in covalent and noncovalent anticancer drug release systems. Carbohydr. Polym. 2020, 242, 116401. [CrossRef]

9. Tian, B.; Liu, Y.; Liu, J. Smart stimuli-responsive drug delivery systems based on cyclodextrin: A review. Carbohydr. Polym. 2021, 251, 116871. [CrossRef]

10. Garrido, P.F.; Calvelo, M.; Blanco-González, A.; Veleiro, U.; Suárez, F.; Conde, D.; Cabezón, A.; Piñeiro, A.; Garcia-Fandino, R. The Lord of the nanorings: Cyclodextrins and the battle against SARS-CoV-2. J. Pharm. Sci. 2020, 588, 119689.

11. García Fernández, J.M.; Ortiz Mellet, C.; Defaye, J. Glyconanocavities: Cyclodextrins and beyond. J. Incl. Phenom. Macrocyl. Chem. 2006, 56, 149-159. [CrossRef]

12. Crini, G. Review: A history of cyclodextrins. Chem. Rev. 2014, 114, 10940-10975. [CrossRef]

13. Zhang, W.-B.; Yu, X.; Wang, C.-L.; Sun, H.-J.; Hsieh, I.-F.; Li, Y.; Dong, X.-H.; Yue, K.; Van Horn, R.; Cheng, S.Z.D. Molecular nanoparticles are unique elements for macromolecular science: From "nanoatoms" to giant molecules. Macromolecules 2014, 47, 1221-1239. [CrossRef]

14. Yin, G.-Z.; Zhang, W.-B.; Cheng, S.Z.D. Giant molecules: Where chemistry, physics, and bio-science meet. Sci. China Chem. 2017, 60, 338-352. [CrossRef]

15. Fernández, M.A.; Silva, O.F.; Vico, R.V.; de Rossi, R.H. Complex systems that incorporate cyclodextrins to get materials for some specific applications. Carbohydr. Res. 2019, 480, 12-34. [CrossRef]

16. Zhang, Y.-M.; Liu, Y.-H.; Liu, Y. Cyclodextrin-based multistimuli-responsive supramolecular assemblies and their biological functions. Adv. Mater. 2020, 32, 1806158. [CrossRef]

17. Gadade, D.D.; Pekamwar, S.S. Cyclodextrin based nanoparticles for drug delivery and theranostics. Adv. Pharm. Bull. 2020, 10, 166-183. [CrossRef]

18. Tian, B.; Liu, J. The classification and application of cyclodextrin polymers: A review. New J. Chem. 2020, 44, 9137-9148. [CrossRef] 
19. Shelley, H.; Babu, R.J. Role of cyclodextrins in nanoparticle-based drug delivery systems. J. Pharm. Sci. 2018, 107, 1741-1753. [CrossRef]

20. Gim, S.; Zhu, Y.; Seeberger, P.; Delbianco, M. Carbohydrate-based nanomaterials for biomedical applications. WIREs Nanomed. Nanobiotechnol. 2019, 11, e1558. [CrossRef]

21. Ortiz-Mellet, C.; Benito, J.M.; García Fernández, J.M.; Law, H.; Chmurski, K.; Defaye, J.; O’Sullivan, M.L.; Caro, H.N. Cyclodextrin-scaffolded glycoclusters. Chem. Eur. J. 1998, 4, 2523-2531. [CrossRef]

22. Vargas-Berenguel, A.; Ortega-Caballero, F.; Casas-Solvas, J.M. Supramolecular chemistry of carbohydrate clusters with cores having guest binding abilities. Mini-Rev. Org. Chem. 2007, 4, 1-14. [CrossRef]

23. Martínez, A.; Ortiz Mellet, C.; García Fernández, J.M. Cyclodextrin-based multivalent glycodisplays: Covalent and supramolecular conjugates to assess carbohydrate-protein interactions. Chem. Soc. Rev. 2013, 42, 4746-4773. [CrossRef] [PubMed]

24. Roy, R.; Shiao, T.C. Glyconanosynthons as powerful scaffolds and building blocks for the rapid construction of multifaceted, dense and chiral dendrimers. Chem. Soc. Rev. 2015, 44, 3924-3941. [CrossRef] [PubMed]

25. Huang, M.L.; Godula, K. Nanoscale materials for probing the biological functions of the glycocalyx. Glycobiology 2016, 26, 797-803. [CrossRef]

26. Zhan, W.; Wei, T.; Yu, Q.; Chen, H. Fabrication of supramolecular bioactive surfaces via $\beta$-cyclodextrin based host-guest interactions. ACS Appl. Mater. Interfaces 2018, 10, 36585-36601. [CrossRef]

27. Wei, T.; Tang, Z.; Yu, Q.; Chen, H. Smart antibacterial surfaces with switchable bacteria-killing and bacteria-releasing capabilities. ACS Appl. Mater. Interfaces 2017, 9, 37511-37523. [CrossRef]

28. Huang, L.; Liu, X.-H.; Zhang, X.-H.; Tan, L.; Liu, C.-J. A highly efficient bactericidal surface based on the co-capture function and photodynamic sterilization. J. Mater. Chem. B 2018, 6, 6831-6841. [CrossRef]

29. Zhan, W.; Wei, T.; Cao, L.; Hu, C.; Qu, Y.; Yu, Q.; Chen, H. Supramolecular platform with switchable multivalent affinity: Photo-reversible capture and release of bacteria. ACS Appl. Mater. Interfaces 2017, 9, 3505-3513. [CrossRef]

30. Qu, Y.; Wei, T.; Zhan, W.; Hu, C.; Cao, L.; Yu, Q.; Chen, H. A reusable supramolecular platform for the specific capture and release of proteins and bacteria. J. Mater. Chem. B 2017, 5, 444-453. [CrossRef]

31. Gade, M.; Paul, A.; Alex, C.; Choudhury, D.; Thulasiram, H.V.; Kikkeri, R. Supramolecular scaffolds on glass slides as sugar based rewritable sensors for bacteria. Chem. Commun. 2015, 51, 6346-6349. [CrossRef]

32. Lee, Y.C.; Lee, R.T. Carbohydrate-protein interactions: Basis of glycobiology. Acc. Chem. Res. 1995, 28, 321-327. [CrossRef]

33. Jayaraman, N. Multivalent ligand presentation as a central concept to study intricate carbohydrate-protein interactions. Chem. Soc. Rev. 2009, 38, 3463-3483. [CrossRef]

34. Cecioni, S.; Imberty, A.; Vidal, S. Glycomimetics versus multivalent glycoconjugates for the design of high affinity lectin ligands. Chem. Rev. 2015, 115, 525-561. [CrossRef]

35. Benito, J.M.; Gómez-García, M.; Ortiz Mellet, C.; Baussanne, I.; Defaye, J.; García Fernández, J.M. Optimizing saccharide-directed molecular delivery to biological receptors: Design, synthesis, and biological evaluation of glycodendrimer-cyclodextrin conjugates. J. Am. Chem. Soc. 2004, 126, 10355-10363. [CrossRef]

36. Connors, K.A. The stability of cyclodextrin complexes in solution. Chem. Rev. 1997, 97, 1325-1357. [CrossRef]

37. Schmidt, B.V.K.J.; Barner-Kowollik, C. Dynamic macromolecular material design-The versatility of cyclodextrin-based host-guest chemistry. Angew. Chem. Int. Ed. 2017, 56, 8350-8369. [CrossRef]

38. Grünstein, D.; Maglinao, M.; Kikkeri, R.; Collot, M.; Barylyuk, K.; Lepenies, B.; Kamena, F.; Zenobi, R.; Seeberger, P.H. Hexameric supramolecular scaffold orients carbohydrates to sense bacteria. J. Am. Chem. Soc. 2011, 133, 13957-13966. [CrossRef]

39. Bavireddi, H.; Vasudeva Murthy, R.; Gade, M.; Sangabathuni, S.; Madhukar Chaudhary, P.; Alex, C.; Lepenies, B.; Kikkeri, R. Understanding carbohydrate-protein interactions using homologous supramolecular chiral Ru(II)-glyconanoclusters. Nanoscale 2016, 8, 19696-19702. [CrossRef]

40. Bavireddi, H.; Vasudeva Murthy, R.; Gade, M.; Sangabathuni, S.; Kikkeri, R. Supramolecular metalloglycodendrimers selectively modulate lectin binding and delivery of Ru(II) complexes into mammalian cells. Org. Biomol. Chem. 2016, 14, 10816-10821. [CrossRef]

41. Bavireddi, H.; Bharatez, P.; Kikkeri, R. Use of Boolean and fuzzy logics in lactose glycocluster research. Chem. Commun. 2013, 49, 9185-9187. [CrossRef] 
42. Zhang, Q.; Cai, Y.; Wang, X.-J.; Xu, J.-L.; Ye, Z.; Wang, S.; Seeberger, P.H.; Yin, J. Targeted photodynamic killing of breast cancer cells employing heptamannosylated $\beta$-cyclodextrin-mediated nanoparticle formation of an adamantane-functionalized BODIPY photosensitizer. ACS Appl. Mater. Interfaces 2016, 8, 33405-33411. [CrossRef]

43. Kang, Y.; Tang, X.; Cai, Z.; Zhang, X. Supra-amphiphiles for functional assemblies. Adv. Funct. Mater. 2016, 26, 8920-8931. [CrossRef]

44. Sun, T.; Wang, Q.; Bi, Y.; Chen, X.; Liu, L.; Ruan, C.; Zhao, Z.; Jiang, C. Supramolecular amphiphiles based on cyclodextrin and hydrophobic drugs. J. Mater. Chem. B 2017, 5, 2644-2654. [CrossRef]

45. Bai, Y.; Liu, C.P.; Song, X.; Zhuo, L.; Bu, H.; Tian, W. Photo- and pH-dual-responsive $\beta$-cyclodextrin-based supramolecular prodrug complex self-assemblies for programmed drug delivery. Chem. Asian J. 2018, 13, 3903-3911. [CrossRef]

46. Yang, T.; Du, G.; Cui, Y.; Yu, R.; Hua, C.; Tian, W.; Zhang, Y. pH-sensitive doxorubicin-loaded polymeric nanocomplex based on $\beta$-cyclodextrin for liver cancer-targeted therapy. Int. J. Nanomed. 2019, 14, 1997-2010. [CrossRef]

47. Varan, G.; Benito, J.M.; Ortiz Mellet, C.; Bilensoy, E. Development of polycationic amphiphilic cyclodextrin nanoparticles for anticancer drug delivery. Beilstein J. Nanotechnol. 2017, 8, 1457-1467. [CrossRef]

48. Méndez-Ardoy, A.; Gomez-Garcia, M.; Geze, A.; Putaux, J.L.; Wouessidjewe, D.; Ortiz Mellet, C.; Defaye, J.; Garcia Fernandez, J.M.; Benito, J.M. Monodisperse nanoparticles from self-assembling amphiphilic cyclodextrins: Modulable tools for the encapsulation and controlled release of pharmaceuticals. Med. Chem. 2012, 8, 524-532. [CrossRef]

49. Sallas, F.; Darcy, R. Amphiphilic cyclodextrins-Advances in synthesis and supramolecular chemistry. Eur. J. Org. Chem. 2008, 957-969. [CrossRef]

50. Sallas, F.; Niikura, K.; Nishimura, S.-I. A practical synthesis of amphiphilic cyclodextrins fully substituted with sugar residues on the primary face. Chem. Commun. 2004, 596-597. [CrossRef]

51. Mazzaglia, A.; Forde, D.; Garozzo, D.; Malvagna, P.; Ravoo, B.J.; Darcy, R. Multivalent binding of galactosylated cyclodextrin vesicles to lectin. Org. Biomol. Chem. 2004, 2, 957-960. [CrossRef]

52. Micali, N.; Villari, V.; Mazzaglia, A.; Monsú Scolaro, L.; Valerio, A.; Rencurosi, A.; Lay, L. Cyclodextrin nanoaggregates and their assembly with protein: A spectroscopic investigation. Nanotechnology 2006, 17, 3239-3244. [CrossRef]

53. Mazzaglia, A.; Valerio, A.; Villari, V.; Rencurosi, A.; Lay, L.; Spadaro, S.; Monsú Scolaro, L.; Micali, N. Probing specific protein recognition by size-controlled glycosylated cyclodextrin nanoassemblies. New J. Chem. 2006, 30, 1662-1668. [CrossRef]

54. McNicholas, S.; Rencurosi, A.; Lay, L.; Mazzaglia, A.; Sturiale, L.; Perez, M.; Darcy, R. Amphiphilic N-glycosylthiocarbamoyl cyclodextrins: synthesis, self-assembly, and fluorimetry of recognition by Lens culinaris lectin. Biomacromolecules 2007, 8, 1851-1857. [CrossRef]

55. Ye, Z.; Zhang, Q.; Wang, S.; Bharate, P.; Varela-Aramburu, S.; Lu, M.; Seeberger, P.H.; Yin, J. Tumour-targeted drug delivery with mannose-functionalized nanoparticles self-assembled from amphiphilic $\beta$-cyclodextrins. Chem. Eur. J. 2016, 22, 15216-15221. [CrossRef]

56. Ortiz Mellet, C.; Méndez-Ardoy, A.; García Fernández, J.M. Click multivalent glycomaterials: Glycoclusters, glycodendrimers, glycopolymers, hybrid glycomaterials, and glycosurfaces. In Click Chemistry in Glycoscience: New Developments and Strategies; Witczak, Z.J., Bielski, R., Eds.; Wiley: Hoboken, NJ, USA, 2013; Chapter 6; pp. 143-182.

57. Wei, P.; Ye, Z.; Cao, S.; Bai, S.; Seeberger, P.H.; Yin, J.; Hu, J. Combination therapy with amphotericin B and doxorubicin encapsulated in mannosylated nanomicelles for visceral leishmaniasis. Coll. Surf. A 2020, 598,124804 . [CrossRef]

58. Fenyvesi, É. Cyclodextrin polymers in the pharmaceutical industry. J. Incl. Phenom. 1988, 6, 537-545. [CrossRef]

59. Simoes, S.M.N.; Rey-Rico, A.; Concheiro, A.; Alvarez-Lorenzo, C. Supramolecular cyclodextrin-based drug nanocarriers. Chem. Commun. 2015, 51, 6275-6289. [CrossRef]

60. Chen, G.; Jiang, M. Cyclodextrin-based inclusion complexation bridging supramolecular chemistry and macromolecular self-assembly. Chem. Soc. Rev. 2011, 40, 2254-2266. [CrossRef]

61. Cakir, N.; Hizal, G.; Becer, C.R. Supramolecular glycopolymers with thermoresponsive self-assembly and lectin binding. Polym. Chem. 2015, 6, 6623-6631. [CrossRef] 
62. Seidi, F.; Shamsabadi, A.A.; Amini, M.; Shabanian, M.; Crespy, D. Functional materials generated by allying cyclodextrin-based supramolecular chemistry with living polymerization. Polym. Chem. 2019, 10, 3674-3711. [CrossRef]

63. Yilmaz, G.; Uzunova, V.; Napier, R.; Becer, C.R. Single-chain glycopolymer folding via host-guest interactions and its unprecedented effect on DC-SIGN binding. Biomacromolecules 2018, 19, 3040-3047. [CrossRef]

64. Nelson, A.; Belitsky, J.M.; Vidal, S.; Joiner, C.S.; Baum, L.G.; Stoddart, J.F. A self-assembled multivalent pseudopolyrotaxane for binding galectin-1. J. Am. Chem. Soc. 2004, 126, 11914-11922. [CrossRef] [PubMed]

65. Yui, N.; Ooya, T. Molecular mobility of interlocked structures exploiting new functions of advanced biomaterials. Chem. Eur. J. 2006, 12, 6730-6737. [CrossRef] [PubMed]

66. Nishide, J.-I.; Kashiwao, K.; Kitauchi, K.; Sasabe, H. Lectin recognition characteristics of carbohydrate-polyrotaxane beads. Mol. Cryst. Liq. Cryst. 2010, 519, 108-114. [CrossRef]

67. Chwalek, M.; Auzély, R.; Fort, S. Synthesis and biological evaluation of multivalent carbohydrate ligands obtained by click assembly of pseudo-rotaxanes. Org. Biomol. Chem. 2009, 7, 1680-1688. [CrossRef] [PubMed]

68. Hu, X.; Gao, J.; Luo, Y.; Wei, T.; Dong, Y.; Chen, G.; Chen, H. One-pot multicomponent synthesis of glycopolymers through a combination of host-guest interaction, thiol-ene, and copper-catalyzed click reaction in water. Macromol. Rapid Commun. 2017, 38, 1700434. [CrossRef] [PubMed]

69. Gómez-García, M.; Benito, J.M.; Rodríguez-Lucena, D.; Yu, J.; Chmurski, K.; Ortiz Mellet, C.; Gutiérrez Gallego, R.; Maestre, A.; Defaye, J.; Garciía Fernández, J.M. Probing secondary carbohydrate-protein interactions with highly dense cyclodextrin-centered heteroglycoclusters: The heterocluster effect. J. Am. Chem. Soc. 2005, 127, 7970-7971. [CrossRef]

70. Jiménez Blanco, J.L.; Ortiz Mellet, C.; García Fernández, J.M. Multivalency in heterogeneous glycoenvironments: Hetero-glycoclusters, -glycopolymers and -glycoassemblies. Chem. Soc. Rev. 2013, 42, 4518-4531. [CrossRef]

71. Müller, C.; Despras, G.; Lindhorst, T.K. Organizing multivalency in carbohydrate recognition. Chem. Soc. Rev. 2016, 45, 3275-3302.

72. Ortiz Mellet, C.; Nierengarten, J.-F.; García Fernández, J.M. Multivalency as an action principle in multimodal lectin recognition and glycosidase inhibition: A paradigm shift driven by carbon-based Glyconanomaterials. J. Mater. Chem. B 2017, 5, 6428-6436. [CrossRef]

73. García-Moreno, M.I.; Ortega-Caballero, F.; Rísquez-Cuadro, R.; Ortiz Mellet, C.; García Fernández, J.M. The impact of heteromultivalency in lectin recognition and glycosidase inhibition: An integrated mechanistic study. Chem. Eur. J. 2017, 23, 6295-6304. [CrossRef]

74. Rísquez-Cuadro, R.; Matsumoto, R.; Ortega-Caballero, F.; Nanba, E.; Higaki, K.; García Fernández, J.M.; Ortiz Mellet, C. Pharmacological chaperones for the treatment of $\alpha$-mannosidosis. J. Med. Chem. 2019, 62, 5832-5843. [CrossRef] [PubMed]

75. González-Cuesta, M.; Ortiz Mellet, C.; García Fernández, J.M. Carbohydrate supramolecular chemistry: Beyond the multivalent effect. Chem. Commun. 2020, 56, 5207-5222. [CrossRef] [PubMed]

76. Liu, S.; Jin, J.; Jia, Y.-G.; Wang, J.; Mo, L.; Chen, X.; Qi, D.; Chen, Y.; Ren, L. Glycopolymers made from polyrotaxanes terminated with bile acids: Preparation, self-assembly, and targeting delivery. Macromol. Biosci. 2019, 19, 1800478. [CrossRef] [PubMed]

77. Miyawaki, A.; Miyauchi, M.; Takashima, Y.; Yamaguchi, H.; Harada, A. Formation of supramolecular isomers; poly[2]rotaxane and supramolecular assembly. Chem. Commun. 2008, 4, 456-458. [CrossRef] [PubMed]

78. Tran, D.N.; Colesnic, D.; de Beaumais, S.A.; Pembouong, G.; Portier, F.; Queijo, A.A.; Vázquez Tato, J.; Zhang, Y.; Ménand, M.; Bouteiller, L.; et al. Cyclodextrin-adamantane conjugates, self-inclusion and aggregation versus supramolecular polymer formation. Org. Chem. Front. 2014, 1, 703-706. [CrossRef]

79. Evenou, P.; Rossignol, J.; Pembouong, G.; Gothland, A.; Colesnic, D.; Barbeyron, R.; Rudiuk, S.; Marcelin, A.-G.; Ménand, M.; Baigl, D.; et al. Bridging $\beta$-cyclodextrin prevents self-Inclusion, promotes supramolecular polymerization, and promotes cooperative interaction with nucleic acids. Angew. Chem. Int. Ed. 2018, 57, 7753-7758. [CrossRef]

80. Cutrone, G.; Benkovics, G.; Malanga, M.; Casas-Solvas, J.M.; Fenyvesi, É.; Sortino, S.; García-Fuentes, L.; Vargas-Berenguel, A. Mannoside and 1,2-mannobioside $\beta$-cyclodextrin-scaffolded NO-photodonors for targeting antibiotic resistant bacteria. Carbohydr. Polym. 2018, 199, 649-660. [CrossRef] 
81. Wang, L.; Gong, C.; Yuan, X.; Wei, G. Controlling the self-assembly of biomolecules into functional nanomaterials through internal interactions and external stimulations: A review. Nanomaterials 2019, 9, 285. [CrossRef]

82. Wei, K.; Li, J.; Chen, G.; Jiang, M. Dual molecular recognition leading to a protein-polymer conjugate and further self-assembly. ACS Macro Lett. 2013, 2, 278-283. [CrossRef]

83. Bono, N.; Ponti, F.; Mantovani, D.; Candiani, G. Non-viral in vitro gene delivery: It is now time to set the bar! Pharmaceutics 2020, 12, 183. [CrossRef] [PubMed]

84. Yin, H.; Kanasty, R.L.; Eltoukhy, A.A.; Vegas, A.J.; Dorkin, J.R.; Anderson, D.G. Nonviral vectors for gene-based therapy. Nat. Rev. Genet. 2014, 15, 541-555. [CrossRef] [PubMed]

85. Lostalé-Seijo, I.; Montenegro, J. Synthetic materials at the forefront of gene delivery. Nat. Rev. Chem. 2018, 2, 258-277. [CrossRef]

86. Ortiz Mellet, C.; Benito, J.M.; García Fernández, J.M. Preorganized, macromolecular, gene-delivery systems. Chem. Eur. J. 2010, 16, 6728-6742. [CrossRef]

87. Jiménez Blanco, J.L.; Benito, J.M.; Ortiz Mellet, C.; García Fernández, J.M. Molecular nanoparticle-based gene delivery systems. J. Drug Deliv. Sci. Technol. 2017, 42, 18-37. [CrossRef]

88. Geng, W.-C.; Huang, Q.; Xu, Z.; Wang, R.; Guo, D.-S. Gene delivery based on macrocyclic amphiphiles. Theranostics 2019, 9, 3094-3106. [CrossRef]

89. Carbajo-Gordillo, A.I.; Jiménez Blanco, J.L.; Benito, J.M.; Lana, H.; Marcelo, G.; Di Giorgio, C.; Przybylski, C.; Hinou, H.; Ceña, V.; Ortiz Mellet, C.; et al. Click Synthesis of size and shape-tunable star polymers with functional macrocyclic cores for synergistic DNA complexation and delivery. Biomacromolecules 2020, 21,5173-5188. [CrossRef]

90. Pan, Y.-C.; Hu, X.-Y.; Guo, D.-S. Biomedical applications of calixarenes: State-of-the-art and perspectives. Angew. Chem. Int. Ed. 2020. [CrossRef]

91. Illescas, B.M.; Pérez-Sánchez, A.; Mallo, A.; Martín-Domenech, Á.; Rodríguez-Crespo, I.; Martín, N. Multivalent cationic dendrofullerenes for gene transfer: Synthesis and DNA complexation. J. Chem. B 2020, 8, 4505-4515. [CrossRef]

92. Carbajo-Gordillo, A.I.; Rodríguez-Lavado, J.; Jiménez Blanco, J.L.; Benito, J.M.; Di Giorgio, C.; Vélaz, I.; Tros de Ilarduya, C.; Ortiz Mellet, C.; García Fernández, J.M. Trehalose-based Siamese twin amphiphiles with tunable self-assembling, DNA nanocomplexing and gene delivery properties. Chem. Commun. 2019, 55, 8227-8230. [CrossRef]

93. Gasparello, J.; Manicardi, A.; Casnati, A.; Corradini, R.; Gambari, R.; Finotti, A.; Sansone, F. Efficient cell penetration and delivery of peptide nucleic acids by an argininocalix[4]arene. Sci. Rep. 2019, 9, 3036. [CrossRef] [PubMed]

94. Minami, K.; Okamoto, K.; Harano, K.; Noiri, E.; Nakamura, E. Hierarchical assembly of siRNA with tetraamino fullerene in physiological conditions for efficient internalization into cells and knockdown. ACS Appl. Mater. Interfaces 2018, 10, 19347-19354. [CrossRef]

95. Manzanares, D.; Araya-Durán, I.; Gallego-Yerga, L.; Játiva, P.; Márquez-Miranda, V.; Canan, J.; Jiménez Blanco, J.L.; Ortiz Mellet, C.; González-Nilo, F.D.; García Fernández, J.M.; et al. Molecular determinants for cyclooligosaccharide-based nanoparticle mediated effective siRNA transfection. Nanomedicine 2017, 12, 1607-1621. [CrossRef]

96. Jiménez Blanco, J.L.; Ortega-Caballero, F.; Blanco-Fernández, L.; Carmona, T.; Marcelo, G.; Martínez-Negro, M.; Aicart, E.; Junquera, E.; Mendicuti, F.; Tros de Ilarduya, C.; et al. Trehalose-based Janus cyclooligosaccharides: The "click" synthesis and DNA-directed assembly into $\mathrm{pH}$-sensitive transfectious nanoparticles. Chem. Commun. 2016, 52, 10117-10120. [CrossRef] [PubMed]

97. Ortiz Mellet, C.; García Fernández, J.M.; Benito, J.M. Cyclodextrin-based gene delivery systems. Chem. Soc. Rev. 2011, 40, 1586-1608. [CrossRef] [PubMed]

98. García Fernández, J.M.; Benito, J.M.; Ortiz Mellet, C. Cyclodextrin-scaffolded glycotransporters for gene delivery. Pure Appl. Chem. 2013, 85, 1825-1845. [CrossRef]

99. Lai, W.-F. Cyclodextrins in non-viral gene delivery. Biomaterials 2014, 35, 401-411. [CrossRef]

100. Przybylski, C.; Benito, J.M.; Bonnet, V.; Ortiz Mellet, C.; García Fernández, J.M. Deciphering of polycationic carbohydrate based non-viral gene delivery agents by ESI-LTQ-Orbitrap using CID/HCD pairwise tandem mass spectrometry. RSC Adv. 2016, 6, 78803-78817. [CrossRef] 
101. Przybylski, C.; Benito, J.M.; Bonnet, V.; Ortiz Mellet, C.; García Fernández, J.M. Toward a suitable structural analysis of gene delivery carrier based on polycationic carbohydrates by electron transfer dissociation tandem mass spectrometry. Anal. Chim. Acta 2016, 948, 62-72. [CrossRef]

102. Przybylski, C.; Benito, J.M.; Bonnet, V.; Ortiz Mellet, C.; García Fernández, J.M. Revealing cooperative binding of polycationic cyclodextrins with DNA oligomers by capillary electrophoresis coupled to mass spectrometry. Anal. Chim. Acta 2018, 1002, 70-81. [CrossRef]

103. Latxague, L.; Gaubert, A.; Barthélémy, P. Recent advances in the chemistry of glycoconjugate amphiphiles. Molecules 2018, 23, 89. [CrossRef] [PubMed]

104. Xu, X.; Wu, Y.-L.; Li, Z.; Loh, X.J. Cyclodextrin-based sustained gene release systems: A supramolecular solution towards clinical applications. Mater. Chem. Front. 2019, 3, 181-192. [CrossRef]

105. Díaz-Moscoso, A.; Patricia Balbuena, P.; Gómez-Garcia, M.; Ortiz Mellet, C.; Benito, J.M.; Le Gourriérec, L.; Di Giorgio, C.; Vierling, P.; Mazzaglia, A.; Micali, N.; et al. Rational design of cationic cyclooligosaccharides as efficient gene delivery systems. Chem. Commun. 2008, 17, 2001-2003. [CrossRef] [PubMed]

106. Ortega-Caballero, F.; Ortiz Mellet, C.; Le Gourriérec, L.; Guilloteau, N.; Di Giorgio, C.; Vierling, P.; Defaye, J.; García Fernández, J.M. Tailoring $\beta$-cyclodextrin for DNA complexation and delivery by homogeneous functionalization at the secondary face. Org. Lett. 2008, 10, 5143-5146. [CrossRef] [PubMed]

107. Byrne, C.; Sallas, F.; Rai, D.K.; Ogier, J.; Darcy, R. Poly-6-cationic amphiphilic cyclodextrins designed for gene delivery. Org. Biomol. Chem. 2009, 7, 3763-3771. [CrossRef] [PubMed]

108. Díaz-Moscoso, A.; Vercauteren, D.; Rejman, J.; Benito, J.M.; Ortiz Mellet, C.; De Smedt, S.C.; García Fernández, J.M. Insights in cellular uptake mechanisms of pDNA-policationic amphiphilic cyclodextrin nanoparticles (CDplexes). J. Control. Release 2010, 143, 318-325. [CrossRef] [PubMed]

109. O’Neill, M.J.; Guoa, J.; Byrne, C.; Darcy, R.; O’Driscoll, C.M. Mechanistic studies on the uptake and intracellular trafficking of novel cyclodextrin transfection complexes by intestinal epithelial cells. Int. J. Pharm. 2011, 413, 174-183. [CrossRef]

110. Méndez-Ardoy, A.; Urbiola, K.; Aranda, C.; Ortiz Mellet, C.; García Fernández, J.M.; Tros de Ilarduya, C. Polycationic amphiphilic cyclodextrin-based nanoparticles for therapeutic dene Delivery. Nanomedicine 2011, 6, 1697-1707. [CrossRef] [PubMed]

111. Bienvenu, C.; Martínez, A.; Jiménez Blanco, J.L.; Di Giorgio, C.; Vierling, P.; Ortiz Mellet, C.; Defaye, J.; García Fernández, J.M. Polycationic amphiphilic cyclodextrins as gene vectors: Effect of the macrocyclic ring size on the DNA complexing and delivery properties. Org. Biomol. Chem. 2012, 10, 5570-5581. [CrossRef] [PubMed]

112. O'Mahony, A.M.; Ogier, J.; Desgranges, S.; Cryan, J.F.; Darcy, R.; O’Driscoll, C.M. A click chemistry route to 2-functionalised PEGylated and cationic $\beta$-cyclodextrins: Co-formulation opportunities for siRNA delivery. Org. Biomol. Chem. 2012, 10, 4954-4960. [CrossRef] [PubMed]

113. O'Mahony, A.M.; Doyle, D.; Darcy, R.; Cryan, J.F.; O’Driscoll, C.M. Characterisation of cationic amphiphilic cyclodextrins for neuronal delivery of siRNA: Effect of reversing primary and secondary face modifications. Eur. J. Pharm. Sci. 2012, 47, 896-903. [CrossRef] [PubMed]

114. O’Mahony, A.M.; Godinho, B.M.D.C.; Ogier, J.; Devocelle, M.; Darcy, R.; Cryan, J.F.; O’Driscoll, C.M. Click-modified cyclodextrins as nonviral vectors for neuronal siRNA delivery. ACS Chem. Neurosci. 2012, 3, 744-752. [CrossRef] [PubMed]

115. O'Mahony, A.M.; Ogier, J.; Darcy, R.; Cryan, J.F.; O’Driscoll, C.M. Cationic and PEGylated amphiphilic cyclodextrins: Co-formulation opportunities for neuronal siRNA delivery. PLoS ONE 2013, 8, e66413. [CrossRef] [PubMed]

116. O’Neill, M.J.; O’Mahony, A.M.; Byrne, C.; Darcy, R.; O’Driscoll, C.M. Gastrointestinal gene delivery by cyclodextrins-In vitro quantification of extracellular barriers. Int. J. Pharm. 2013, 456, 390-399.

117. Martínez, A.; Bienvenu, C.; Jiménez Blanco, J.L.; Vierling, P.; Ortiz Mellet, C.; García Fernández, J.M.; Di Giorgio, C. Amphiphilic oligoethyleneimine- $\beta$-cyclodextrin "click" clusters for enhanced DNA delivery. J. Org. Chem. 2013, 78, 8143-8148. [CrossRef]

118. Villari, V.; Mazzaglia, A.; Darcy, R.; O’Driscoll, C.M.; Micali, N. Nanostructures of cationic amphiphilic cyclodextrin complexes with DNA. Biomacromolecules 2013, 14, 811-817. [CrossRef]

119. Godinho, B.M.D.C.; Ogier, J.R.; Darcy, R.; O’Driscoll, C.M.; Cryan, J.F. Self-assembling modified $\beta$-cyclodextrin nanoparticles as neuronal siRNA delivery vectors: Focus on Huntington's disease. Mol. Pharm. 2013, 10, 640-649. [CrossRef] 
120. McCarthy, J.; O’Neill, M.J.; Bourre, L.; Walsh, D.; Quinlan, A.; Hurley, G.; Ogier, J.; Shanahan, F.; Melgar, S.; Darcy, R.; et al. Gene silencing of TNF-alpha in a murine model of acute colitis using a modified cyclodextrin delivery system. J. Control. Release 2013, 168, 28-34. [CrossRef] [PubMed]

121. O'Mahony, A.M.; Cronin, M.F.; McMahon, A.; Evans, J.C.; Daly, K.; Darcy, R.; O’Driscoll, C.M. Biophysical and structural characterisation of nucleic acid complexes with modified cyclodextrins using circular dichroism. J. Pharm. Sci. 2014, 103, 1346-1355. [CrossRef] [PubMed]

122. Hibbitts, A.; O’Mahony, A.M.; Forde, E.; Nolan, L.; Ogier, J.; Desgranges, S.; Darcy, R.; MacLoughlin, R.; O'Driscoll, C.M.; Cryan, S.A. Early-stage development of novel cyclodextrin siRNA nanocomplexes allows for successful postnebulization transfection of bronchial epithelial cells. J. Aerosol Med. Pulm. Drug Deliv. 2014, 27, 466-477. [CrossRef] [PubMed]

123. Gallego-Yerga, L.; Lomazzi, M.; Franceschi, V.; Sansone, F.; Ortiz Mellet, C.; Donofrio, G.; Casnati, A.; García Fernández, J.M. Cyclodextrin- and calixarene-based polycationic amphiphiles as gene delivery systems: A structure-activity relationship study. Org. Biomol. Chem. 2015, 13, 1708-1723. [CrossRef] [PubMed]

124. Evans, C.; McCarthy, J.; Torres-Fuentes, C.; Cryan, J.F.; Ogier, J.; Darcy, R.; Watson, R.W.; O’Driscoll, C.M. Cyclodextrin mediated delivery of NF-kB and SRF siRNA reduces the invasion potential of prostate cancer cells in vitro. Gene Ther. 2015, 22, 802-810. [CrossRef] [PubMed]

125. Fitzgerald, K.A.; Guo, J.; Tierney, E.G.; Curtin, C.M.; Malhotra, M.; Darcy, R.; O’Brien, F.J.; O’Driscoll, C.M. The use of collagen-based scaffolds to simulate prostate cancer bone metastases with potential for evaluating delivery of nanoparticulate gene therapeutics. Biomaterials 2015, 66, 53-66. [CrossRef] [PubMed]

126. Pflueger, I.; Charrat, C.; Ortiz Mellet, C.; García Fernández, J.M.; Di Giorgio, C.; Benito, J.M. Cyclodextrin-Based Facial Amphiphiles: Assessing the impact of the hydrophilic-lipophilic balance in the self-assembly, DNA complexation and gene delivery capabilities. Org. Biomol. Chem. 2016, 14, 10037-10049. [CrossRef]

127. Fitzgerald, K.A.; Guo, J.; Raftery, R.M.; Mencía Castaño, I.; Curtin, C.M.; Gooding, M.; Darcy, R.; O’ Brien, F.J.; O' Driscoll, C.M. Nanoparticle-mediated siRNA delivery assessed in a 3D co-culture model simulating prostate cancer bone metastasis. Int. J. Pharm. 2016, 511, 1058-1069. [CrossRef]

128. Remaut, K.; De Clercq, E.; Andries, V.; Rombouts, K.; Van Gils, V.; Cicchelero, V.; Vandenbussche, I.; Van Praet, S.; Benito, J.M.; García Fernández, J.M.; et al. Aerosolized non-viral nucleic acid delivery in the vaginal tract of pigs. Pharm. Res. 2016, 3, 384-394. [CrossRef]

129. Minnaert, A.-K.; Dakwar, G.R.; Benito, J.M.; García Fernández, J.M.; Ceelen, W.; De Smedt, S.C.; Remaut, K. High-Pressure Nebulization as Application Route for the Peritoneal Administration of siRNA Complexes. Macromol. Biosci. 2017, 17, 1700024.

130. Martínez-Negro, M.; Caracciolo, G.; Palchetti, S.; Pozzi, D.; Capriotti, A.L.; Cavaliere, C.; Laganà, A.; Ortiz Mellet, C.; Benito, J.M.; García Fernández, J.M.; et al. Biophysics and protein corona analysis of Janus cyclodextrin-DNA nanocomplexes. Efficient cellular transfection on cancer cells. Biochim. Biophys. Acta Gen. Subj. 2017, 1861, 1737-1749. [CrossRef]

131. Gallego-Yerga, L.; Benito, J.M.; Blanco-Fernández, L.; Martínez-Negro, M.; Vélaz, I.; Aicart, E.; Junquera, E.; Ortiz Mellet, C.; Tros de Ilarduya, C.; García Fernández, J.M. Plasmid-templated control of DNA-cyclodextrin nanoparticle morphology through molecular vector design for effective gene delivery. Chem. Eur. J. 2018, 24, 3825-3835. [CrossRef]

132. Singh, R.P.; Hidalgo, T.; Cazade, P.-A.; Darcy, R.; Cronin, M.F.; Dorin, I.; O’Driscoll, C.M.; Thompson, D. Self-assembled cationic $\beta$-cyclodextrin nanostructures for siRNA delivery. Mol. Pharmaceutics 2019, 16, 1358-1366. [CrossRef]

133. Martín-Moreno, A.; Jiménez Blanco, J.L.; Mosher, J.; Swanson, D.R.; García Fernández, J.M.; Sharma, A.; Ceña, V.; Muñoz-Fernández, M.A. Nanoparticle-delivered HIV peptides to dendritic cells a promising approach to generate a therapeutic vaccine. Pharmaceutics 2020, 12, 656. [CrossRef] [PubMed]

134. Gallego-Yerga, L.; Blanco-Fernández, L.; Urbiola, K.; Carmona, T.; Marcelo, G.; Benito, J.M.; Mendicuti, F.; Tros de Ilarduya, C.; Ortiz Mellet, C.; García Fernández, J.M. Host-guest mediated DNA templation of polycationic supramolecules for hierarchical nanocondensation and the delivery of gene material. Chem. Eur. J. 2015, 21, 12093-12104. [CrossRef] [PubMed] 
135. Balbuena, P.; Lesur, D.; González Álvarez, M.J.; Mendicuti, F.; Ortiz Mellet, C.; García Fernández, J.M. One-pot regioselective synthesis of $2^{\mathrm{I}}, 3^{\mathrm{I}}$-O-(o-xylylene)-capped cyclomaltooligosaccharides: Tailoring the topology and supramolecular properties of cyclodextrins. Chem Commun. 2007, 31, 3270-3272. [CrossRef] [PubMed]

136. González-Álvarez, M.J.; Balbuena, P.; Ortiz Mellet, C.; García Fernández, J.M.; Mendicuti, F. Study of the conformational and self-aggregation properties of $2^{\mathrm{I}}, 3^{\mathrm{I}}-\mathrm{O}-(\mathrm{o}-\mathrm{Xylylene})$-per-O-Me- $\alpha$ - and $-\beta$-cyclodextrins by fluorescence and molecular modeling. J. Phys. Chem. B 2008, 112, 13717-13729. [CrossRef]

137. Gonzalez-Álvarez, M.J.; Vicente, J.; Ortiz Mellet, C.; García Fernández, J.M.; Mendicuti, F. Thermodynamics of the dimer formation of $2^{\mathrm{I}}, 3^{\mathrm{I}}-\mathrm{O}$-(o-xylylene)-per-O-Me- $\gamma$-cyclodextrin: Fluorescence, molecular mechanics and molecular dynamics. J. Fluoresc. 2009, 19, 975-988. [CrossRef]

138. González-Álvarez, M.J.; Méndez-Ardoy, A.; Benito, J.M.; García Fernández, J.M.; Mendicuti, F. Self-association of a naphthalene-capped- $\beta$-cyclodextrin through cooperative strong hydrophobic interactions. J. Photochem. Photobiol. A 2011, 223, 25-36. [CrossRef]

139. González-Álvarez, M.J.; Mayordomo, N.; Gallego-Yerga, L.; Ortiz Mellet, C.; Mendicuti, F. Improving inclusion capabilities of permethylated cyclodextrins by appending a cap-like aromatic moiety. Tetrahedron 2012, 68, 2961-2972. [CrossRef]

140. González-Álvarez, M.J.; Benito, J.M.; García Fernández, J.M.; Ortiz Mellet, C.; Mendicuti, F. Influence of the macroring size on the self-association thermodynamics of cyclodextrins with a double-linked naphthalene at the secondary face. J. Phys. Chem. B 2013, 117, 5472-5485. [CrossRef]

141. Balbuena, P.; Gonçalves-Pereira, R.; Jiménez Blanco, J.L.; García-Moreno, M.I.; Lesur, D.; Ortiz Mellet, C.; García Fernández, J.M. o-Xylylene protecting group in carbohydrate chemistry: Application to the regioselective protection of a single vic-diol segment in cyclodextrins. J. Org. Chem. 2013, 78, 1390-1403. [CrossRef]

142. Gallego-Yerga, L.; González-Álvarez, M.J.; Mayordomo, N.; Santoyo-González, F.; Benito, J.M.; Ortiz Mellet, C.; Mendicuti, F.; García Fernández, J.M. Dynamic self-assembly of polycationic clusters based on cyclodextrins for $\mathrm{pH}$-Sensitive DNA nanocondensation and delivery by component design. Chem. Eur. J. 2014, 22, 6622-6627. [CrossRef]

143. Neva, T.; Carmona, T.; Benito, J.M.; Przybylski, C.; Ortiz Mellet, C.; Mendicuti, F.; García Fernández, J.M. Xylylene clips for the topology-guided control of the inclusion and self-assembling properties of cyclodextrins. J. Org. Chem. 2018, 83, 5588-5597. [CrossRef] [PubMed]

144. Neva, T.; Carmona, T.; Benito, J.M.; Przybylski, C.; Ortiz Mellet, C.; Mendicuti, F.; García Fernández, J.M. Dynamic control of the self-assembling properties of cyclodextrins by the interplay of aromatic and host-guest interactions. Front. Chem. 2019, 7, 72. [CrossRef] [PubMed]

145. Neva, T.; Ortiz Mellet, C.; García Fernández, J.M.; Benito, J.M. Multiply-linked cyclodextrin-aromatic hybrids: Caps, hinges and clips. J. Carbohydr. Chem. 2019, 38, 470-493. [CrossRef]

146. Neva, T.; Carbajo-Gordillo, A.I.; Benito, J.M.; Lana, H.; Marcelo, G.; Ortiz Mellet, C.; Tros de Ilarduya, C.; Mendicuti, F.; García Fernández, J.M. Tuning the topological landscape of DNA-cyclodextrin nanocomplexes by molecular design. Chem. Eur. J. 2020, 26, 15259-15269. [CrossRef]

147. Guo, J.; Ogier, J.R.; Desgranges, S.; Darcy, R.; O’Driscoll, C. Anisamide-targeted cyclodextrin nanoparticles for siRNA delivery to prostate tumours in mice. Biomaterials 2012, 33, 7775-7784. [CrossRef]

148. O’Mahony, A.M.; Desgranges, S.; Ogier, J.; Quinlan, A.; Devocelle, M.; Darcy, R.; Cryan, J.F.; O'Driscoll, C.M. In vitro investigations of the efficacy of cyclodextrin-siRNA complexes modified with lipid-PEG-octaarginine: Towards a formulation strategy for non-viral neuronal siRNA delivery. Pharm. Res. 2013, 30, 1086-1098. [CrossRef]

149. Aranda, C.; Urbiola, K.; Méndez Ardoy, A.; García Fernández, J.M.; Ortiz Mellet, C.; Tros de Ilarduya, C. Targeted gene delivery by new folate-polycationic amphiphilic cyclodextrin-DNA nanocomplexes in vitro and in vivo. Eur. J. Pharm. Biopharm. 2013, 85, 390-397. [CrossRef]

150. Gooding, M.; Malhotra, M.; McCarthy, D.J.; Godinho, B.M.D.C.; Cryan, J.F.; Darcy, R.; O'Driscoll, C.M. Synthesis and characterization of rabies virus glycoprotein tagged amphiphilic cyclodextrins for siRNA delivery in human glioblastoma cells: In vitro analysis. Eur. J. Pharm. Sci. 2015, 71, 80-92. [CrossRef]

151. Malhotra, M.; Gooding, M.; Sallas, F.; Evans, J.C.; Fitzgerald, K.A.; Evans, J.C.; Darcy, R.; O’Driscoll, C.M. A novel, anisamide-targeted cyclodextrin nanoformulation for siRNA delivery to prostate cancer cells expressing the sigma-1 receptor. Int. J. Pharm. 2016, 499, 131-145. 
152. Malhotra, M.; Guo, J.; Guo, J.F.; O’Shea, J.P.; Hanrahan, K.; O’Neill, A.; Landry, W.D.; Griffin, B.T.; Darcy, R.; Watson, R.W.; et al. Folate-targeted amphiphilic cyclodextrin.siRNA nanoparticles for prostate cancer therapy exhibit PSMA mediated uptake, therapeutic gene silencing in vitro and prolonged circulation in vivo. Nanomedicine Nanotechnol. Biol. Med. 2016, 12, 2341-2351.

153. Evans, J.C.; Malhotra, M.; Fitzgerald, K.A.; Guo, J.; Cronin, M.F.; Fitzgerald, K.A.; Cronin, M.F.; Curtin, C.M.; O'Brien, F.J.; Darcy, R.; et al. Formulation and evaluation of anisamide-targeted amphiphilic cyclodextrin nanoparticles to promote therapeutic gene silencing in a 3D prostate cancer bone metastases model. Mol. Pharmaceutics 2017, 14, 42-52. [CrossRef] [PubMed]

154. Guo, J.; Russell, E.G.; Darcy, R.; Cotter, T.G.; McKenna, S.L.; Cahill, M.R.; O’Driscoll, C.M. Antibody-targeted cyclodextrin-based nanoparticles for siRNA delivery in the treatment of acute myeloid leukemia: Physicochemical characteristics, in vitro mechanistic studies, and ex vivo patient derived therapeutic efficacy. Mol. Pharmaceutics 2017, 14, 940-952. [CrossRef] [PubMed]

155. Evans, J.C.; Malhotra, M.; Sweeney, K.; Darcy, R.; Nelson, C.C.; Hollier, B.G.; O’Driscoll, C.M. Folate-targeted amphiphilic cyclodextrin nanoparticles incorporating a fusogenic peptide deliver therapeutic siRNA and inhibit the invasive capacity of 3D prostate cancer tumours. Int. J. Pharm. 2017, 532, 511-518. [CrossRef] [PubMed]

156. Díaz-Moscoso, A.; Guilloteau, N.; Bienvenu, C.; Mendez-Ardoy, A.; Jiménez Blanco, J.L.; Benito, J.M.; Le Gourriérec, L.; Di Giorgio, C.; Vierling, P.; Defaye, J.; et al. Mannosyl-coated nanocomplexes from amphiphilic cyclodextrins and pDNA for site-specific gene delivery. Biomaterials 2011, 32, 7263-7273. [CrossRef]

157. Cendret, V.; François-Heude, M.; Méndez-Ardoy, A.; Moreau, V.; García Fernández, J.M.; Djedaïni-Pilard, F. Design and synthesis of a "click" high-mannose oligosaccharide mimic emulating Man 8 binding affinity towards Con A. Chem. Commun. 2012, 48, 3733-3735. [CrossRef]

158. Rodríguez-Lavado, J.; de La Mata, M.; Jiménez-Blanco, J.L.; García-Moreno, M.I.; Benito, J.M.; Díaz-Quintana, A.; Sánchez-Alcázar, J.A.; Higaki, K.; Nanba, E.; Ohno, K.; et al. Targeted delivery of pharmacological chaperones for Gaucher disease to macrophages by a mannosylated cyclodextrin carrier. Org. Biomol. Chem. 2014, 12, 2289-2301. [CrossRef]

159. François-Heude, M.; Méndez-Ardoy, A.; Cendret, V.; Lafite, P.; Daniellou, R.; Ortiz Mellet, C.; García Fernández, J.M.; Moreau, V.; Djedaïni-Pilard, F. Synthesis of high-mannose oligosaccharide analogues through click chemistry: True functional mimics of their natural counterparts against lectins? Chem. Eur. J. 2015, 21, 1978-1991. [CrossRef]

160. González-Cuesta, M.; Goyard, D.; Nanba, E.; Higaki, K.; García Fernández, J.M.; Renaudet, O.; Ortiz Mellet, C. Multivalent glycoligands with lectin/enzyme dual specificity: Self-deliverable glycosidase regulators. Chem. Commun. 2019, 55, 12845-12848. [CrossRef]

161. Gadekar, A.; Bhowmick, S.; Pandit, A. A glycotherapeutic approach to functionalize biomaterial-based systems. Adv. Funct. Mater. 2020, 1910031. [CrossRef]

162. Chen, F.; Huang, G. Application of glycosylation in targeted drug delivery. Eur. J. Med. Chem. 2019, 182, 111612. [CrossRef]

163. Kawakami, S.; Hashida, M. Glycosylation-mediated targeting of carriers. J. Control. Release 2014, 190, 542-555. [CrossRef] [PubMed]

164. Méndez-Ardoy, A.; Díaz-Moscoso, A.; Ortiz Mellet, C.; Di Giorgio, C.; Vierling, P.; Benito, J.M.; García Fernández, J.M. Harmonized tuning of nucleic acid and lectin binding properties with multivalent cyclodextrins for macrophage-selective gene delivery. RSC Adv. 2015, 5, 76464-76471. [CrossRef]

165. McMahon, A.; O’Neill, M.J.; Gomez, E.; Donohue, R.; Forde, D.; Darcy, R.; O’Driscoll, C.M. Targeted gene delivery to hepatocytes with galactosylated amphiphilic cyclodextrins. J. Pharm. Pharmacol. 2012, 64, 1063-1073. [CrossRef] [PubMed]

166. Donohue, R.; Mazzaglia, A.; Ravoo, B.J.; Darcy, R. Cationic $\beta$-cyclodextrin bilayer vesicles. Chem. Commun. 2002, 7, 2864-2865. [CrossRef]

167. Symens, N.; Méndez-Ardoy, A.; Díaz-Moscoso, A.; Sánchez-Fernández, E.; Remaut, K.; Demeester, J.; García Fernández, J.M.; De Smedt, S.C.; Rejman, J. Efficient transfection of hepatocytes mediated by mRNA complexed to galactosylated cyclodextrins. Bioconjugate Chem. 2012, 23, 1276-1289. [CrossRef]

168. Baussanne, I.; Benito, J.M.; Ortiz Mellet, C.; García Fernández, J.M.; Law, H.; Defaye, J. Synthesis and comparative lectin-binding affinity of mannosyl-coated $\beta$-cyclodextrin-dendrimer constructs. Chem. Commun. 2000, 1489-1490. [CrossRef] 
169. Smiljanic, N.; Moreau, V.; Yockot, D.; Benito, J.M.; García Fernández, J.M.; Djedaïni-Pilard, F. Supramolecular control of oligosaccharide-protein interactions: Switchable and tunable ligands for concanavalin A based on $\beta$-cyclodextrin. Angew. Chem. Int. Ed. 2006, 45, 5465-5468. [CrossRef]

170. Aguilar-Moncayo, E.M.; Guilloteau, N.; Bienvenu, C.; Jiménez Blanco, J.L.; Di Giorgio, C.; Vierling, P.; Benito, J.M.; Ortiz Mellet, C.; García Fernández, J.M. Cyclodextrin-scaffolded amphiphilic aminoglucoside clusters: Self-assembling and gene delivery capabilities. New J. Chem. 2014, 38, 5215-5225. [CrossRef]

171. Guilloteau, N.; Bienvenu, C.; Charrat, C.; Jiménez Blanco, J.L.; Díaz-Moscoso, A.; Ortiz Mellet, C.; García Fernández, J.M.; Vierling, P.; Di Giorgio, C. Cell uptake mechanisms of glycosylated cationic pDNA-cyclodextrin nanoparticles. RSC Adv. 2015, 5, 29135-29144. [CrossRef]

172. Kihara, F.; Arima, H.; Tsutsumi, T.; Hirayama, F.; Uekama, K. Effects of structure of polyamidoamine dendrimer on gene transfer efficiency of the dendrimer conjugate with $\alpha$-cyclodextrin. Bioconjugate Chem. 2002, 13, 1211-1219. [CrossRef]

173. Kihara, F.; Arima, H.; Tsutsumi, T.; Hirayama, F.; Uekama, K. In vitro and in vivo gene transfer by an optimized $\alpha$-cyclodextrin conjugate with polyamidoamine dendrimer. Bioconjugate Chem. 2003, 14, 342-350. [CrossRef] [PubMed]

174. Hayashi, Y.; Higashi, T.; Motoyama, K.; Mori, Y.; Jono, H.; Ando, Y.; Arima, H. Design and evaluation of polyamidoamine dendrimer conjugate with PEG, $\alpha$-cyclodextrin and lactose as a novel hepatocyte-selective gene carrier in vitro and in vivo. J. Drug Target. 2013, 21, 487-496. [CrossRef]

175. Motoyama, K.; Mitsuyasu, R.; Akao, C.; Tanaka, T.; Ohyama, A.; Sato, N.; Higashi, T.; Arima, H. Design and Evaluation of Thioalkylated Mannose-Modified Dendrimer (G3)/ $\alpha$-cyclodextrin conjugates as antigen-presenting cell-selective siRNA carriers. AAPS J. 2014, 16, 1298-1308. [CrossRef] [PubMed]

176. Hayashi, Y.; Higashi, T.; Motoyama, K.; Hiroumi Jono, H.; Yukio Ando, Y.; Onodera, R.; Arima, H. Hepatocyte-targeted delivery of siRNA polyplex with PEG-modified lactosylated dendrimer/cyclodextrin conjugates for transthyretin-related amyloidosis therapy. Biol. Pharm. Bull. 2019, 42, 1679-1688. [CrossRef] [PubMed]

177. Motoyama, K.; Mitsuyasu, R.; Akao, C.; Hashim, I.I.A.; Sato, N.; Tanaka, T.; Higashi, T.; Arima, H. Potential use of thioalkylated mannose-modified dendrimer (G3)/ $\alpha$-cyclodextrin conjugate as an NF- $\mathrm{kB}$ siRNA carrier for the treatment of fulminant hepatitis. Mol. Pharmaucetics 2015, 12, 3129-3136. [CrossRef] [PubMed]

178. Voskuhl, J.; Stuart, M.C.A.; Ravoo, B.J. Sugar-decorated sugar vesicles: Lectin-carbohydrate recognition at the surface of cyclodextrin vesicles. Chem. Eur. J. 2010, 16, 2790-2796. [CrossRef]

179. Vico, R.V.; Voskuhl, J.; Ravoo, B.J. Multivalent interaction of cyclodextrin vesicles, carbohydrate guests, and lectins: A kinetic investigation. Langmuir 2011, 27, 1391-1397. [CrossRef]

180. Ravoo, B.J.; Darcy, R. Cyclodextrin bilayer vesicles. Angew. Chem. Int. Ed. 2000, 39, 4324-4326. [CrossRef]

181. Falvey, P.; Lim, C.W.; Darcy, R.; Revermann, T.; Karst, U.; Giesbers, M.; Marcelis, A.T.M.; Lazar, A.; Coleman, A.W.; Reinhoudt, D.N.; et al. Bilayer vesicles of amphiphilic cyclodextrins: Host membranes that recognize guest molecules. Chem. Eur. J. 2005, 11, 1171-1180. [CrossRef]

182. de Vries, W.C.; Tesch, M.; Studer, A.; Ravoo, B.J. Molecular recognition and immobilization of ligand-conjugated redox-responsive polymer nanocontainers. ACS Appl. Mater. Interfaces 2017, 9, 41760-41766. [CrossRef]

183. Schibilla, F.; Voskuhl, J.; Fokina, N.A.; Jeremy, E.P.; Dahl, J.E.P.; Schreiner, P.R.; Ravoo, B.J. Host-guest complexes of cyclodextrins and nanodiamonds as a strong non-covalent binding motif for self-sssembled nanomaterials. Chem. Eur. J. 2017, 23, 16059-16065. [CrossRef] [PubMed]

184. Ehrmann, S.; Chu, C.-W.; Kumari, S.; Silberreis, K.; Böttcher, C.; Dernedde, J.; Ravoo, B.J.; Haag, R. A toolbox approach for multivalent presentation of ligand-receptor recognition on a supramolecular scaffold. J. Mater. Chem. B 2018, 6, 4216-4222. [CrossRef] [PubMed]

185. Gallego-Yerga, L.; de la Torre, C.; Sansone, F.; Casnati, F.; Ortiz Mellet, C.; García Fernández, J.M.; Ceña, V. Synthesis, self-assembly and anticancer drug encapsulation and delivery properties of cyclodextrin-based giant amphiphiles. Carbohydr. Polym. 2021, 252, 117135. [CrossRef] [PubMed]

186. Gallego-Yerga, L.; Posadas, I.; de la Torre, C.; Ruiz-Almansa, J.; Sansone, F.; Ortiz Mellet, C.; Casnati, A.; García Fernández, J.M.; Ceña, V. Docetaxel-loaded nanoparticles assembled from $\beta$ - cyclodextrin/calixarene giant surfactants: Physicochemical properties and cytotoxic effect in prostate cancer and glioblastoma cells. Front. Pharmacol. 2017, 8, 249. [CrossRef] [PubMed] 
187. Gallego-Yerga, L.; Lomazzi, M.; Sansone, F.; Ortiz Mellet, C.; Casnati, A.; García Fernandez, J.M. Glycoligand-targeted core-shell nanospheres with tunable drug release profiles from calixarene-cyclodextrin heterodimers. Chem. Commun. 2014, 50, 7440-7443. [CrossRef]

188. Samanta, A.; Ravoo, B.J. Magnetic separation of proteins by a self-assembled supramolecular ternary complex. Angew. Chem. Int. Ed. 2014, 53, 12946-12950. [CrossRef]

189. Hu, C.; Wu, J.; Wei, T.; Zhan, W.; Qu, Y.; Pan, Y.; Yu, Q.; Chen, H. A supramolecular approach for versatile biofunctionalization of magnetic nanoparticles. J. Mater. Chem. B 2018, 6, 2198-2203. [CrossRef]

190. Oz, Y.; Abdouni, Y.; Yilmaz, G.; Becer, C.R.; Sanyal, A. Magnetic glyconanoparticles for selective lectin separation and purification. Polym. Chem. 2019, 10, 3351-3361. [CrossRef]

191. Bavireddi, H.; Kikkeri, R. Glyco- $\beta$-cyclodextrin capped quantum dots: Synthesis, cytotoxicity and optical detection of carbohydrate-protein interactions. Analyst 2012, 137, 5123-5127. [CrossRef]

192. Oikonomou, M.; Wang, J.; Carvalho, J.J.; Velders, A.H. Ternary supramolecular quantum-dot network flocculation for selective lectin detection. Nano Res. 2016, 9, 1904-1912. [CrossRef]

193. Luo, G.-F.; Chen, W.-H.; Lei, Q.; Qiu, W.-X.; Liu, Y.-X.; Cheng, Y.-J.; Zhang, X.-Z. A triple-collaborative strategy for high-performance tumor therapy by multifunctional mesoporous silica-coated gold nanorods. Adv. Funct. Mater. 2016, 26, 4339-4350. [CrossRef]

194. Qi, Z.; Bharate, P.; Lai, C.-H.; Ziem, B.; Böttcher, C.; Schulz, A.; Beckert, F.; Hatting, B.; Mülhaupt, R.; Seeberger, P.H.; et al. Multivalency at interfaces: Supramolecular carbohydrate-functionalized graphene derivatives for bacterial capture, release, and disinfection. Nano Lett. 2015, 15, 6051-6057. [CrossRef] [PubMed]

195. Aykaç, A.; Martos-Maldonado, M.C.; Casas-Solvas, J.M.; Quesada-Soriano, I.; García-Maroto, F.; García-Fuentes, L.; Vargas-Berenguel, A. $\beta$-Cyclodextrin-bearing gold glyconanoparticles for the development of site specific drug delivery systems. Langmuir 2014, 30, 234-242. [CrossRef] [PubMed]

196. Massaro, M.; Riela, S.; Lo Meo, P.; Noto, R.; Cavallaro, G.; Milioto, S.; Lazzara, G. Functionalized halloysite multivalent glycocluster as a new drug delivery system. J. Mater. Chem. B 2014, 2, 7732-7738. [CrossRef] [PubMed]

197. Massaro, M.; Riela, S.; Baiamonte, C.; Jiménez Blanco, J.L.; Giordano, C.; Lo Meo, P.; Milioto, S.; Noto, R.; Parisi, F.; Pizzolanti, G.; et al. Dual drug-loaded halloysite hybrid-based glycocluster for sustained release of hydrophobic molecules. RSC Adv. 2016, 6, 87935-87944. [CrossRef]

198. Cutrone, G.; Li, X.; Casas-Solvas, J.M.; Menendez-Miranda, M.; Qiu, J.; Benkovics, G.; Constantin, D.; Malanga, M.; Moreira-Alvarez, B.; Costa-Fernandez, J.M.; et al. Design of engineered cyclodextrin derivatives for spontaneous coating of highly porous metal-organic framework nanoparticles in aqueous media. Nanomaterials 2019, 9, 1103. [CrossRef]

199. Hapiot, F.; Menuel, S.; Ferreira, M.; Léger, B.; Bricout, H.; Tilloy, S.; Monflier, E. Catalysis in cyclodextrin-based unconventional reaction media: Recent developments and future opportunities. ACS Sustainable Chem. Eng. 2017, 5, 3598-3606. [CrossRef]

200. Zhu, X.; Xu, G.; Chamoreau, L.-M.; Zhang, Y.; Mouriès-Mansuy, V.; Fensterbank, L.; Bistri-Aslanoff, O.; Sylvain Roland, S.; Sollogoub, M. Permethylated NHC-capped $\alpha$ - and $\beta$-cyclodextrins $\left(\mathrm{ICyD}^{\mathrm{Me}}\right)$ regioselective and enantioselective gold-catalysis in pure water. Chem. Eur. J. 2020, in press. [CrossRef]

201. Morillo, E.; Madrid, F.; Lara-Moreno, A.; Villaverde, J. Soil bioremediation by cyclodextrins. A review. Int. J. Pharm. 2020, 591, 119943. [CrossRef]

202. Muñoz, J.; Crivillers, N.; Ravoo, B.J.; Mas-Torrent, M. Cyclodextrin-based superparamagnetic host vesicles as ultrasensitive nanobiocarriers for electrosensing. Nanoscale 2020, 12, 9884-9889. [CrossRef]

203. Zhao, Y.-Y.; Yang, J.-M.; Jin, X.-Y.; Cong, H.; Ge, Q.-M.; Liu, M.; Tao, Z. Recent development of supramolecular sensors constructed by hybridization of organic macrocycles with nanomaterials. Curr. Org. Chem. 2020, 24, 265-290. [CrossRef]

204. Casulli, M.A.; Taurino, I.; Carrara, S.; Hayashita, T. Integration methods of cyclodextrins on gold and carbon electrodes for electrochemical sensors. C J. Carbon Res. 2019, 5, 78. [CrossRef]

205. Luo, H.; Chen, L.-X.; Ge, Q.-M.; Liu, M.; Tao, Z.; Zhou, Y.-H.; Cong, H. Applications of macrocyclic compounds for electrochemical sensors to improve selectivity and sensitivity. J. Incl. Phenom. Macrocycl. Chem. 2019, 95, 171-198. [CrossRef]

206. Oliveri, V.; Vecchio, G. Metallocyclodextrins in medicinal chemistry. Future Med. Chem. 2018, 10, 663-677. [CrossRef] 
207. Guillen-Poza, P.A.; Sánchez-Fernández, E.M.; Artigas, G.; García Fernández, J.M.; Hinou, H.; Ortiz Mellet, C.; Nishimura, S.-I.; Garcia-Martin, F. Amplified detection of breast cancer autoantibodies using MUC1-based Tn antigen mimics. J. Med. Chem. 2020, 63, 8524-8533. [CrossRef]

208. Yao, X.; Mu, J.; Zeng, L.; Lin, J.; Nie, Z.; Jiang, X.; Huang, P. Stimuli-responsive cyclodextrin-based nanoplatforms for cancer treatment and theranostics. Mater. Horiz. 2019, 6, 846-870. [CrossRef]

209. Yu, G.; Chen, X. Host-guest chemistry in supramolecular theranostics. Theranostics 2019, 9, 3041-3074. [CrossRef]

210. Braga, S.S. Cyclodextrins: Emerging medicines of the new millennium. Biomolecules 2019, 9, 801. [CrossRef]

211. Bermejo, I.A.; Navo, C.D.; Castro-López, J.; Guerreiro, A.; Jiménez-Moreno, E.; Sánchez Fernández, E.M.; García-Martín, F.; Hinou, H.; Nishimura, S.-I.; García Fernández, J.M.; et al. Synthesis, conformational analysis and in vivo assays of an anti-cancer vaccine that features an unnatural antigen based on an $\mathrm{sp}^{2}$-iminosugar fragment. Chem. Sci. 2020, 11, 3996-4006. [CrossRef]

212. Wankar, J.; Kotla, N.G.; Gera, S.; Rasala, S.; Abhay Pandit, A.; Rochev, Y.A. Recent advances in host-guest self-assembled cyclodextrin carriers: Implications for responsive drug delivery and biomedical engineering. Adv. Funct. Mater. 2020, 30, 1909049. [CrossRef]

213. García-Moreno, M.I.; de la Mata, M.; Sánchez-Fernández, E.M.; Juan, M.; Benito, J.M.; Díaz-Quintana, A.; Fustero, S.; Nanba, E.; Higaki, K.; Sánchez-Alcázar, J.A.; et al. Fluorinated chaperone- $\beta$-cyclodextrin formulations for $\beta$-glucocerebrosidase activity enhancement in neuronopathic Gaucher disease. J. Med. Chem. 2017, 60, 1829-1842. [CrossRef] [PubMed]

Publisher's Note: MDPI stays neutral with regard to jurisdictional claims in published maps and institutional affiliations.

(C) 2020 by the authors. Licensee MDPI, Basel, Switzerland. This article is an open access article distributed under the terms and conditions of the Creative Commons Attribution (CC BY) license (http://creativecommons.org/licenses/by/4.0/). 